\title{
Analysis and Application on Controlling Thick Hard Roof Caving with Deep-Hole Position Presplitting Blasting
}

\author{
Baobao Chen $\mathbb{I}^{1,2}$ and Changyou Liu $\mathbb{i}^{1,2}$ \\ ${ }^{1}$ Key Laboratory of Deep Coal Resource Mining, School of Mines, Ministry of Education of China, \\ China University of Mining and Technology, Xuzhou 221116, China \\ ${ }^{2}$ State Key Laboratory of Coal Resources and Safe Mining, China University of Mining and Technology, Xuzhou 221116, China
}

Correspondence should be addressed to Changyou Liu; lcycumt@cumt.edu.cn

Received 3 August 2018; Accepted 24 September 2018; Published 17 October 2018

Academic Editor: Chiara Bedon

Copyright (c) 2018 Baobao Chen and Changyou Liu. This is an open access article distributed under the Creative Commons Attribution License, which permits unrestricted use, distribution, and reproduction in any medium, provided the original work is properly cited.

\begin{abstract}
For the thick hard roof (THR) in Datong mining area, mining operations often led to large-scale hanging-roof and frequent and strong strata behavior, threatening mining safety seriously. Based on the instability mechanism, the fracture model for THR was established, including rock blocks articulation and combined cantilever beam, and the limit initial and periodic intervals of THR were determined to be $36.0 \mathrm{~m}$ and $8.0 \mathrm{~m}$, respectively. The study proposed the deep-hole presplitting blasting (DPB) for weakening THR for mitigating strong strata behaviors. Blasting-induced fracture characteristics were calculated, determining the charging coefficient and holes spacing. LS-DYNA was employed for establishing a DPB model to analyze crack evolution under the synergistic action of blasting stress wave and detonation gas and the attenuation characteristics for rock peak particle velocity, verifying the rationality of blasting parameters. Field measurement analysis indicated that the immediate roof induced a timely collapse to fill the goaf and the THR was effectively cut off near the presplitting line. Meanwhile, the working resistance was utilized with safety allowance. The field application showed the DPB on controlled THR caving achieved the significant effect.
\end{abstract}

\section{Introduction}

In the Datong Mine area, coal is mined from Jurassic and Carboniferous coal seams at present, which occur below multilayer 10-25 m complex sandstone roofs. Rock mass has high strength and strong integrity, with the linear density of fracture only being $1.1 \mathrm{strip} / \mathrm{m}$. In the process of mining, the thick hard roof (THR) easily forms the large-sized hanging, inducing energy accumulated and abutment pressure extended far [1]. When the limit span of THR is reached, the sudden fracturing would lead to complex migration and strong strata behaviors, including the coal wall spalling, roadside deformation and instability, supports breaking-off, and pillars being crushed $[2,3]$. Furthermore, the selection on supports type with matchless performance and low efficiency for controlling THR would worsen the working face condition, threatening the safety and high efficiency. Consequently, presplitting controlling measures and supports selection should be synergistically employed for controlling THR.

To reduce the strong pressure behavior, positive controlling measures should be employed on presplitting and weakening THR in advance for decreasing caving intervals $[4,5]$. The rock blasting and hydraulic fracturing have been applied for weakened THR and dealing with stress concentration [6-8]. Meanwhile, the deep-hole presplitting blasting (DPB), with convenient operation and huge economic benefits, was widely used in mine-induced stress transferred and rock mass fractured, achieving a remarkable technical effect $[9,10]$. DPB application could actively weaken the integrity of THR between blasting holes at the specific position, form the presetting angle and the interpenetrated fracturing zone, and effectively reduce the length of roof suspension. Near the presplitting line, THR breaks into rock blocks with optimized caving intervals. Meanwhile, 
blasting the fracturing zone effectively cuts off the transferring way of stress, and achieves stress relief to some extent, which mitigates the strata behavior. Domestic and foreign scholars have carried out many related studies on the structure characteristics of the roof initial caving, the presplitting mechanism and techniques for controlling THR migration. Liu et al. analyzed the support resistance variation under the different combination of layer key-stratums caving and combined selecting reasonable support type by using hydraulic fracturing technology to control THR, achieving good effect on the pressure behavior [11]. Yu et al. put forward explosive or liquid carbon dioxide blasting to weaken roofs and large pillar for reducing stress concentration degree through surface drilling $[8,12]$. Wang et al. focused on the initial weighting interval of thick roof in shallow depth seams, employed LS-DYNA3D simulation of DPB to reveal the blasting-controlled roof caving mechanism, and optimized blasting parameters, achieving the expected effect on-site [13]. Yang et al. proposed the DPB technology confined blasting in high pressure water-filled medium instead of the conventional air medium, the result showing a significant technical effect on roof presplitting and pressure relief, but the application of the technique was restricted because of the technical complexity and various limitations on the procedure [14]. Ning et al. analyzed the mining-induced movement and breaking characteristics of the double-layer THR via microseismic monitoring in longwall top-coal caving working face. After adopting the systematic long-hole blasting, the longwall panel could be smoothly extracted with low-frequency instability [15].

From the viewpoint of the safety controlling roof, the DPB could effectively reduce the size of breaking roof, especially the suspended length of the THR, alleviating the strong strata behaviors. However, the above research generally aimed at the presplitting of THR initial caving, and lacked the study on the synergistic controlling roof between the working resistance of the support and the reasonable periodic caving intervals as well as the optimization of the blasting technical parameters. In the study, according to the THR occurrence characteristics of the 8939 working face in Xinzhouyao Mine of Datong Mining area, theoretical analysis was employed for analyzing the action relation between THR caving intervals and working resistance of supports, obtaining the reasonable blasted horizon, the initial presplitting caving interval, and periodic caving interval with presplitting angle. The characteristics and influencing factors of blasting fracturing were analyzed, and meanwhile, the fracture evolution and the rock peak particle velocity (PPV) attenuation were simulated with LS-DYNA, which discussed and determined the rationality of the optimized blasting technical parameters. Subsequently, the presplitted roof collapse characteristics and support resistance were observed and analyzed through field measurements. Consequently, the rationality and efficiency of the DPB were verified on reducing the caving intervals and controlling the strong strata behavior.

\section{Fracture Characteristics and Caving Intervals Controlling Mechanism for THR}

2.1. Engineering Geology Conditions. The 8939 working face has an average coal thickness of $7.2 \mathrm{~m}$ and the dip angle of $3^{\circ}$, which is characterized by the stable occurrence. The longwall-mechanized top caving is applied for mining along strike, with an advancing length of $1176.0 \mathrm{~m}$ and the face length of $104.5 \mathrm{~m}$. Mining height is $3.0 \mathrm{~m}$, with a caving ratio being $1: 1.4$. The layout of working face is shown in Figure 1. Immediate roof is $1.8 \mathrm{~m}$ mudstone and $2.7 \mathrm{~m}$ siltstone, the main roof above which is composed of $13.7 \mathrm{~m}$ medium sandstone and $14.2 \mathrm{~m}$ gritstone. The uniaxial compressive and tensile strength of the medium sandstone are $63.5 \mathrm{MPa}$ and $6.05 \mathrm{MPa}$, respectively, which belongs to typical THR. Lithological characteristics are shown in Figure 2. With no joints and high stability of the rock, the main roof does not break readily as the face advances, inducing the largesized hanging roof and increasing the possibility of strong strata behavior. Therefore, the presplitting on THR is expected to form vertical weaken planes, reduce the sizes of caved blocks, and thereby improve mining safety degree [16].

\subsection{Characteristics of the THR Initial Breaking. With ad-} vancing the working face, when the limit span is reached, the THR is broken up into "V" -shaped structure. For the THR thickness is large, the fractured roof produces horizontal compression and contacting friction after rotary $[17,18]$, which is balanced with the overburden loading under the synergistic action of supports, as shown in Figure 3(a). Where $H, l$, and $\theta$ are the thickness, length, and rotating angle of THR blocks, respectively, $a$ is the height of the articulated surface, $\Delta h$ is the roof movement subsidence, $q$ is the uniform distributed overburden loading, $\varphi$ is the internal friction angle of rock mass, and $B$ is the support width. The mechanical model is shown in Figure 3(b).

According to Figure 3(b), the geometric relation could be obtained as follows:

$$
a=\frac{1}{2 \cos \theta}\left(H-l \frac{1-\cos \theta}{\sin \theta}\right)=\frac{1}{2 \cos \theta}\left(H-l \tan \frac{\theta}{2}\right) \text {. }
$$

For rock blocks remaining stable before contacting gangue, the moment balance is

$$
T(H-a-\Delta h)=\frac{q l^{2}}{2} .
$$

Taking $\tan \varphi$ as the friction coefficient of the THR articulated surface [19], the friction force $R_{0}$ between rock blocks is obtained as follows:

$$
R_{0}=\tan \varphi \frac{2 q l^{2}}{2 h-3 l \sin \theta}=\tan \varphi \frac{2 q l^{2}}{2 h-3 \Delta h}
$$

Considering the impacting action of the THR initial breaking, the top coal is reserved instead of caved for filling 


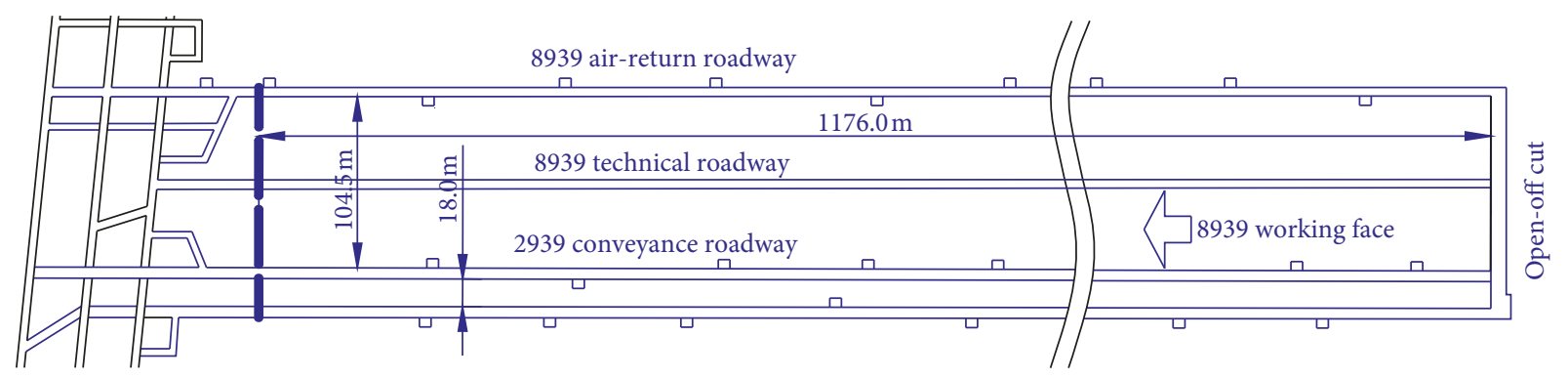

(a)

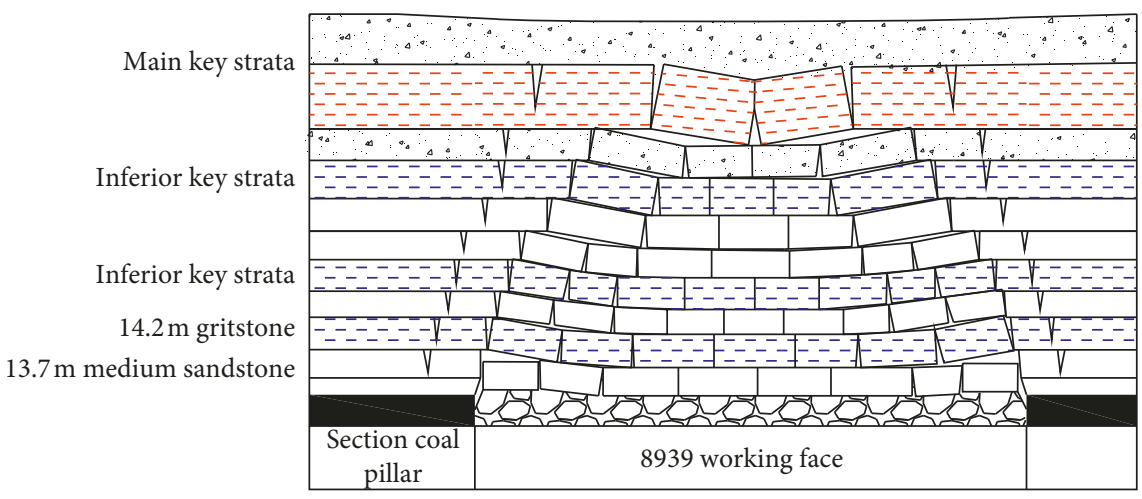

(b)

FIgURe 1: Location plan of 8939 working face. (a) Plane layout and (b) vertical section of the collapse.

\begin{tabular}{|c|c|c|c|c|c|c|c|c|c|c|c|}
\hline & Number & $\begin{array}{l}\text { Buried } \\
\text { depth }\end{array}$ & Columnar & $\begin{array}{c}\text { Min } \sim \text { Max } \\
\text { Average } \\
\text { thickness }(\mathrm{m})\end{array}$ & Lithology & $\begin{array}{l}\text { Density } \\
\mathrm{kg} / \mathrm{m}^{2}\end{array}$ & $\begin{array}{c}\text { Elastic } \\
\text { modulus (GPa) }\end{array}$ & $\begin{array}{l}\text { Poisson's } \\
\text { ratio }\end{array}$ & $\begin{array}{c}\text { Cohesion } \\
(\mathrm{MPa})\end{array}$ & $\begin{array}{l}\text { Friction } \\
\text { angle }\left({ }^{\circ}\right)\end{array}$ & $\begin{array}{c}\text { Tensile } \\
\text { strength }(\mathrm{GPa})\end{array}$ \\
\hline \multirow{11}{*}{ 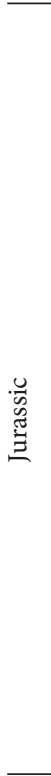 } & 9 & 307.6 & & $\frac{12.8 \sim 16.8}{15.0}$ & Finestone & 2530 & 28.65 & 0.21 & 1.56 & 27.03 & 5.63 \\
\hline & 8 & 322.6 & & $\frac{2.8 \sim 6.1}{4.4}$ & $\begin{array}{c}\text { Sandy } \\
\text { mudstone }\end{array}$ & 2356 & 19.96 & 0.25 & 0.92 & 22.88 & 3.42 \\
\hline & 7 & 327.0 & & $\frac{0.2 \sim 0.8}{0.4}$ & $\begin{array}{c}10 \# \\
\text { Coal } \\
\end{array}$ & 1350 & 17.65 & 0.24 & 1.21 & 26.50 & 2.65 \\
\hline & 6 & 327.4 & & $\frac{3.2 \sim 3.7}{3.5}$ & Siltstone & 2670 & 31.55 & 0.23 & 2.06 & 25.26 & 4.80 \\
\hline & 5 & 330.9 & & $\frac{9.5 \sim 21.7}{14.2}$ & Gritstone & 2520 & 41.25 & 0.22 & 1.86 & 29.12 & 4.86 \\
\hline & 4 & 345.1 & & $\frac{3.5 \sim 4.7}{4.2}$ & $\begin{array}{c}\text { Fine } \\
\text { sandstone }\end{array}$ & 2670 & 34.67 & 0.18 & 2.10 & 25.30 & 2.59 \\
\hline & 3 & 349.3 & 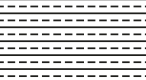 & $\frac{11.5 \sim 15.7}{13.7}$ & $\begin{array}{l}\text { Medium } \\
\text { sandstone }\end{array}$ & 2580 & 28.65 & 0.21 & 1.79 & 24.95 & 6.05 \\
\hline & 2 & 363.0 & & $\frac{2.1 \sim 3.3}{2.7}$ & Finestone & 2520 & 24.86 & 0.24 & 1.69 & 28.36 & 2.83 \\
\hline & 1 & 365.7 & & $\frac{0.9 \sim 2.9}{1.8}$ & $\begin{array}{c}\text { Sandy } \\
\text { mudstone }\end{array}$ & 2356 & 19.96 & 0.25 & 0.92 & 22.88 & 3.42 \\
\hline & Coal & 367.5 & & $\frac{5.2 \sim 9.1}{7.2}$ & $\begin{array}{c}\text { 11\# 12\# } \\
\text { Coal }\end{array}$ & 1320 & 17.63 & 0.26 & 0.86 & 24.63 & 1.28 \\
\hline & Floor & 374.7 & & $\frac{1.7 \sim 5.1}{3.4}$ & Finestone & 2530 & 28.65 & 0.21 & 1.56 & 27.03 & 5.63 \\
\hline
\end{tabular}

FIgURE 2: Local lithological characteristics.

goaf to act as a cushion layer of the THR at the initial stage of production in the working face. Therefore, $13.7 \mathrm{~m}$ medium sandstone is determined as the initial broken-articulated strata, and the relation between the support working resistance and the initial intervals is shown in the following equation: 


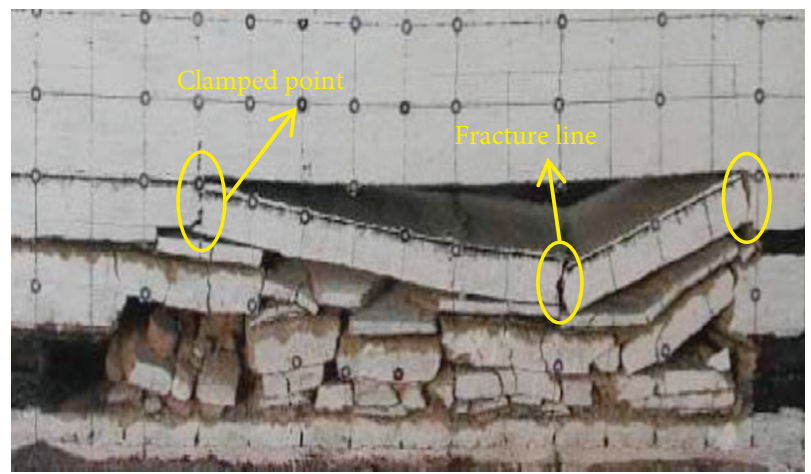

(a)

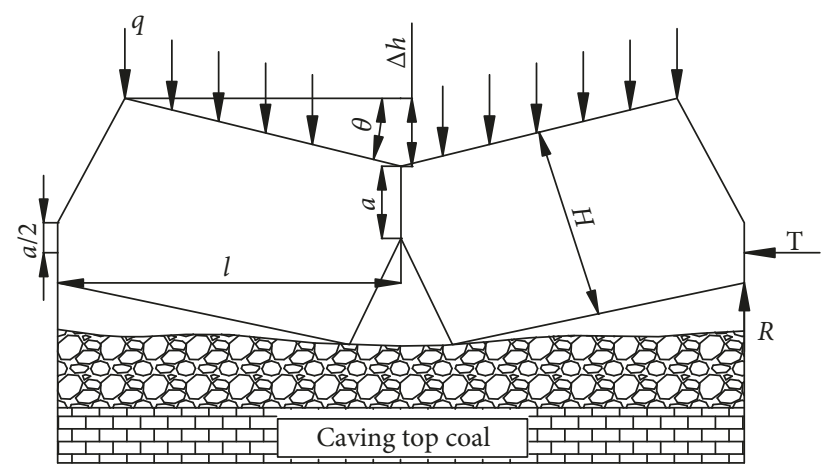

(b)

FIgURE 3: Mechanical analysis on the THR initial breaking.

$$
\left\{\begin{array}{l}
\Delta h=3.0-(1.8+2.7) * 0.33-4.2 * 0.3=0.24, \\
\frac{P}{B}=R_{t}+R_{1}+R_{2}+(q l-R), \\
294+710.1+\left(461.82 l-0.466 * \frac{923.64 l^{2}}{2 * 13.7-3 * 0.24}\right) \\
=\frac{6000}{1.5}(\mathrm{KN}) .
\end{array}\right.
$$

With the existing support resistance of $6000 \mathrm{KN}$, the critical length of the articulated block is determined with $18.8 \mathrm{~m}$. On the basis of safe production on-site, the limit initial caving interval of the roof is set to be $L_{e}=36.0 \mathrm{~m}$. Therefore, the location of presplitting is determined near the open-off cut, $18.0 \mathrm{~m}$ and $36.0 \mathrm{~m}$ from the open-off cut, respectively.

\subsection{Synergetic Controlling on the THR Periodic Caving and Supports}

2.3.1. Characteristics of the THR Periodic Caving Interval. After the initial collapse of the THR, with advancing the working face, the hanging dimension is large enough, leading to a cantilever structure with the free end in the goaf (Figure 4(a)). Therefore, the mechanical model of the cantilever beam with uniformly distributed loading is proposed and employed for analyzing characteristics of the THR periodic breaking [11], as shown in Figure 4(b).

The following stress components of the cantilever beam are obtained [20]:

$$
\left\{\begin{array}{l}
\sigma_{x}=-\frac{6 q}{h^{3}} y\left(x+l_{z}\right)^{2}+\frac{4 q}{h^{3}} y^{3}-\frac{3 q}{5 h} y, \\
\sigma_{y}=-\frac{2 q}{h^{3}} y^{3}+\frac{3 q}{2 h} y-\frac{q}{2}, \\
\tau_{x y}=\frac{6 q}{h^{3}}\left(x+l_{z}\right) y^{2}-\frac{3 q}{2 h}\left(x+l_{z}\right),
\end{array}\right.
$$

where $\sigma_{x}, \sigma_{y}$, and $\tau_{x y}$ are the horizontal, vertical, and shear stress components, respectively, and $l_{z}$ is the half length of the periodic caving interval.

Combined with the stress distribution characteristics of the cantilever beam, the horizontal tensile stress at the fixed end $\left(l_{z},-h / 2\right)$ reaches the maximum. Consequently, the fracture of rock mass conforms to

$$
\left.\sigma_{x}\right|_{\left(l_{z},-h / 2\right)}=\frac{12 q l_{z}^{2}}{h^{2}}-\frac{q}{5} \geq \sigma_{\mathrm{t}} .
$$

Therefore, the limit periodic caving interval $l_{z}$ could be obtained:

$$
L_{z}=2 h \sqrt{\left(\frac{\sigma_{\mathrm{t}}}{12 q}+\frac{1}{60}\right)} .
$$

2.3.2. Determination on the Thickness of Cantilever Stratification and Loading. For the large area roof suspended before THR periodic breaking, the caving interval of the upper thin and soft roof is consistent with the lower THR. Considering the fracturing angle of the rock, the hanging roof presents inverted trapezoid. Therefore, the "immediate roof" combined cantilever beam structure is put forward $[11,12]$, and the caving height full of the goaf is taken as the structure thickness. The overburden loading is mainly carried by the articulated layer, under which the THR with the cantilever structure acts on the support. The broken and instability structure is shown in Figure 5. The total thickness of the cantilever beam is

$$
\left\{\begin{array}{l}
\sum_{i=1}^{3}\left(k_{i}-1\right) h_{i}=6.0<h_{m}=7.2<\sum_{i=1}^{4}\left(k_{i}-1\right) h_{i}=7.4, \\
H_{\mathrm{z}}=\sum h_{i},
\end{array}\right.
$$

where $H_{z}$ is the cantilever beam thickness, $k_{i}$ is the coefficient of bulk increase, $1.33, h_{m}$ is the mining thickness, and $h_{i}$ is the strata layer thickness.

The presplitting layer is determined with numbers $1-4$, that is, $1.8 \mathrm{~m}$ sandy mudstone, $2.7 \mathrm{~m}$ finestone, $13.7 \mathrm{~m}$ medium sandstone, and $4.2 \mathrm{~m}$ finestone are the layers of the 


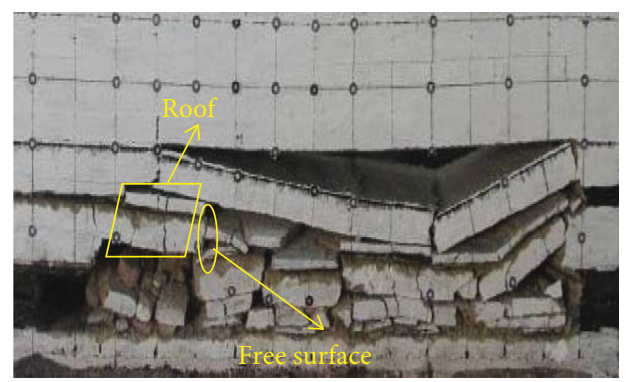

(a)



(b)

FIGURE 4: Load-bearing characteristics of the roof structure with cantilever supported condition.

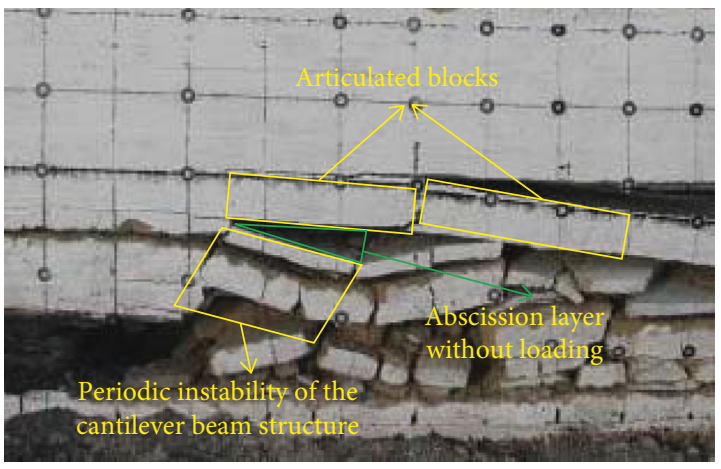

(a)

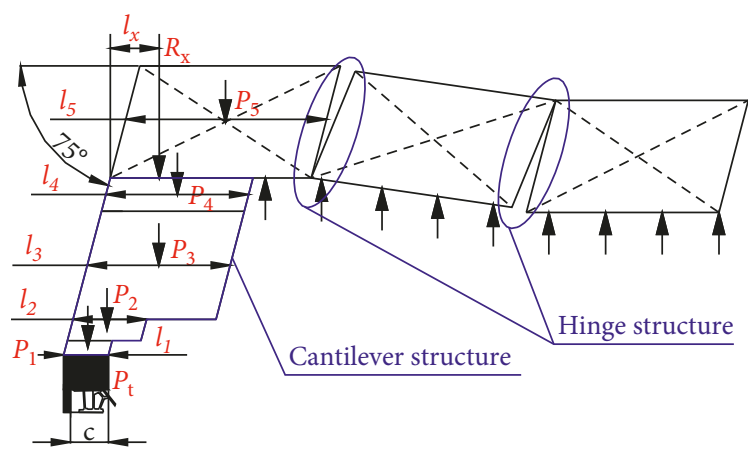

(b)

FIGURE 5: Structure characteristics of the combined cantilever beam-hinge structure of overlying strata.

cantilever beam. The vertical height of presplitting holes, consistent with the total thickness of the structure, is not less than $22.4 \mathrm{~m}$, indicating the $13.7 \mathrm{~m}$ medium sandstone is completely in the scope of presplitting.

Supposing the volume force is $\gamma_{i}$ and elastic modulus is $E_{i}$ of layered strata, where $i=1,2, \mathrm{~m}, \ldots n$. Combined with the key strata theory, the rock-bearing capacity $\left(q_{n}\right)_{m}$ could be obtained [21]:

$$
\left\{\begin{array}{l}
\left(q_{n}\right)_{m}=\frac{E_{m} h_{m}^{3}\left(\gamma_{m} h_{m}+\gamma_{m+1} h_{m+1}+\cdots+\gamma_{n} h_{n}\right)}{E_{m} h_{m}^{3}+E_{m+1} h_{m+1}^{3}+\cdots+E_{n} h_{n}^{3}}, \\
\left(q_{n-1}\right)_{m}<\left(q_{n}\right)_{m}>\left(q_{n+1}\right)_{m},
\end{array}\right.
$$

where $\left(q_{n}\right)_{m}$ is the loading exerted by $n$ layer on $m$ layer rock mass. When loading accords with Equation (9), $q_{m}=\left(q_{n}\right)_{m}$ could be determined. Subsequently, combined with Equation (7), periodic caving intervals of the layered cantilever beam are shown in Table 1.

\subsubsection{Determination on the Presplitting Periodic Intervals of} THR. Combined with the parameters of periodic intervals and the cantilever beam shown in Table 1, considering $14.2 \mathrm{~m}$ gritstone forming the articulated structure, the support working resistance is determined with the loading of $22.4 \mathrm{~m}$ combined cantilever beam and the additional loading applied by articulated strata. According to the mechanical characteristics of the combined cantilever beam, the critical stability condition is obtained:

$$
\begin{aligned}
F= & B \cdot \frac{1}{c}\left[P_{\mathrm{t}} h_{\mathrm{t}}+\frac{1}{2} \sum_{i=1}^{4} P_{i}\left(h_{i} \cot \alpha_{i}+l_{i}\right)+\sum_{j=2}^{4} \sum_{i=1}^{j-1} P_{j} h_{i} \cot \alpha_{i}\right. \\
& \left.+R_{x}\left(\frac{1}{3} l_{x}+\sum_{i=1}^{4} h_{i} \cot \alpha_{i}\right)\right],
\end{aligned}
$$

where $P_{\mathrm{t}}$ is the top coal unit weight, $c$ is the horizontal distance between the equivalent action point and coal wall, $l_{i}$ is the layer periodic caving dimension, $P_{i}=\gamma_{i} h_{i} l_{i}, R_{x}$ is the additional load of articulated blocks acting on the cantilever beam, $l_{x}$ is the acting length of the additional load point on the layered strata, $\alpha_{i}$ is the fracturing angle of roof, simplified as $80^{\circ}$, and $\theta$ is the presplitting angle. As shown in Equation (10), the main controlling factors of presplitting are the periodic presplitting intervals and angle. Based on the cantilever beam parameters, the critical working resistance could be obtained:

$$
P \geq 25500+R_{x}\left(\frac{1}{3} l_{x}+\sum_{i=1}^{4} h_{i} \cot \alpha\right) .
$$

Because of the support working resistance exceeding 25.5 MN, in order to alleviate the strata behavior and ensure 
TABLE 1: Characteristics of strata loading and caving intervals.

\begin{tabular}{|c|c|c|c|c|c|c|c|c|}
\hline No & Lithology & $\begin{array}{l}\text { Thickness } \\
(\mathrm{m})\end{array}$ & $\begin{array}{c}q_{n}=\gamma h \\
(\mathrm{KPa})\end{array}$ & Loading (KPa) & $\begin{array}{l}\text { Load } \\
\text { strata }\end{array}$ & $\begin{array}{l}\text { Uniaxial tensile } \\
\text { strength }(\mathrm{MPa})\end{array}$ & $\begin{array}{c}\text { Periodic caving } \\
\text { interval }(\mathrm{m})\end{array}$ & Remark \\
\hline 9 & $\begin{array}{c}\text { Fine } \\
\text { sandstone }\end{array}$ & 15.0 & 378.0 & - & - & 5.63 & - & \\
\hline 8 & $\begin{array}{c}\text { Sandy } \\
\text { mudstone }\end{array}$ & 4.4 & 103.7 & $q_{8}>\left(q_{9}\right)_{8}=9.6$ & 8 & 3.42 & 8.6 & \multirow{3}{*}{ Loading stratum } \\
\hline 7 & Coal & 0.4 & 5.4 & - & - & 2.65 & - & \\
\hline 6 & Siltstone & 3.5 & 93.5 & $\begin{array}{c}\left(q_{6}+q_{7}\right)>\left(q_{8}\right)_{6}= \\
89.7\end{array}$ & $6-7$ & 4.80 & 14.2 & \\
\hline 5 & Gritstone & 14.2 & 379.2 & $\begin{aligned}\left(q_{8}\right)_{5} & =564.3>\left(q_{9}\right)_{5} \\
& =511.6\end{aligned}$ & $5-8$ & 2.59 & 33.7 & Hinged strata \\
\hline 4 & $\begin{array}{c}\text { Fine } \\
\text { sandstone }\end{array}$ & 4.2 & 105.8 & $q_{4}>\left(q_{5}\right)_{4}=14.5$ & 4 & 2.86 & 9.9 & \multirow{4}{*}{$\begin{array}{c}\text { Combined } \\
\text { cantilever beam }\end{array}$} \\
\hline 3 & $\begin{array}{l}\text { Medium } \\
\text { sandstone }\end{array}$ & 13.7 & 405.1 & $\begin{aligned}\left(q_{4}\right)_{3} & =497.3>\left(q_{5}\right)_{3} \\
& =464.5\end{aligned}$ & $3-4$ & 6.05 & 18.8 & \\
\hline 2 & $\begin{array}{c}\text { Fine } \\
\text { sandstone }\end{array}$ & 2.7 & 68.1 & $q_{2}>\left(q_{3}\right)_{2}=2.1$ & 2 & 2.83 & 9.7 & \\
\hline 1 & $\begin{array}{c}\text { Sandy } \\
\text { mudstone }\end{array}$ & 1.8 & 42.4 & $q_{1}>\left(q_{2}\right)_{1}=21.3$ & 1 & 3.42 & 5.9 & \\
\hline
\end{tabular}

support's safe operation, it is necessary to presplit the THR and control migration. After $13.7 \mathrm{~m}$ medium sandstone presplitted, the limit length of the cantilever beam is the reasonable THR caving interval. For the $14.2 \mathrm{~m}$ gritstone forming the articulated structure, the additional loading decreases with the cantilever length shortening $[8,22]$. The mechanical model after presplitting is shown in Figure 6. After reducing the periodic intervals, the support critical stability condition is shown in Equation (12). The variation curve between the presplitting angles and periodic caving intervals is shown in Figure 7.

$$
\left\{\begin{array}{l}
256383 L_{z}^{2}+4998410 L_{z} \times \cot \theta+32160 L_{z} \\
\quad+782481-23220000=0 \\
256383 L_{z}^{2}+4998410 L_{z} \times \cot \theta+324455 \\
\quad \times \cot \theta+36988 L_{z}+1819713-23220000=0 .
\end{array}\right.
$$

As shown in Figure 7, the curve between the presplitting angle and the periodic caving interval is approximately linear. The limit periodic interval is $9.0 \mathrm{~m}$, with the corresponding presplitting horizontal angle is $0^{\circ}$. However, the smaller presplitting angle may lead to roof broken and cutting-off near the presplitting position, increasing the management difficulty. However, the drilling workload and charging difficulty increase with the rise of the horizontal rotation angle, and the location is relatively complicated. Meanwhile, the horizontal rotation angle varying from $5^{\circ}$ to $10^{\circ}$ has little influence on the presplitting effecting $[1,4]$, and the corresponding periodic presplitting intervals are $7.5 \mathrm{~m}-8.4 \mathrm{~m}$. Therefore, considering the presplitting angle, the periodic interval, and drilling workload, the optimal presplitting interval and blasting-hole horizontal rotation angle are set to be $8.0 \mathrm{~m}$ and $7^{\circ}$, respectively.

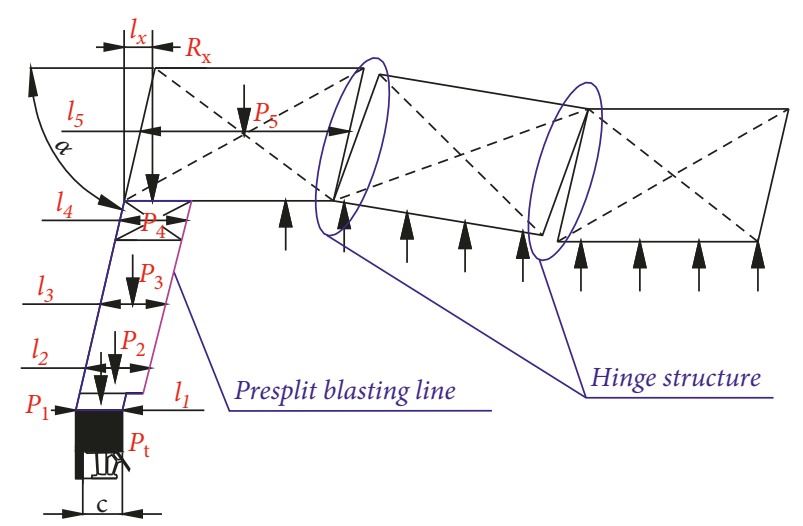

Figure 6: Mechanical model of the combined cantilever beam after presplitting.

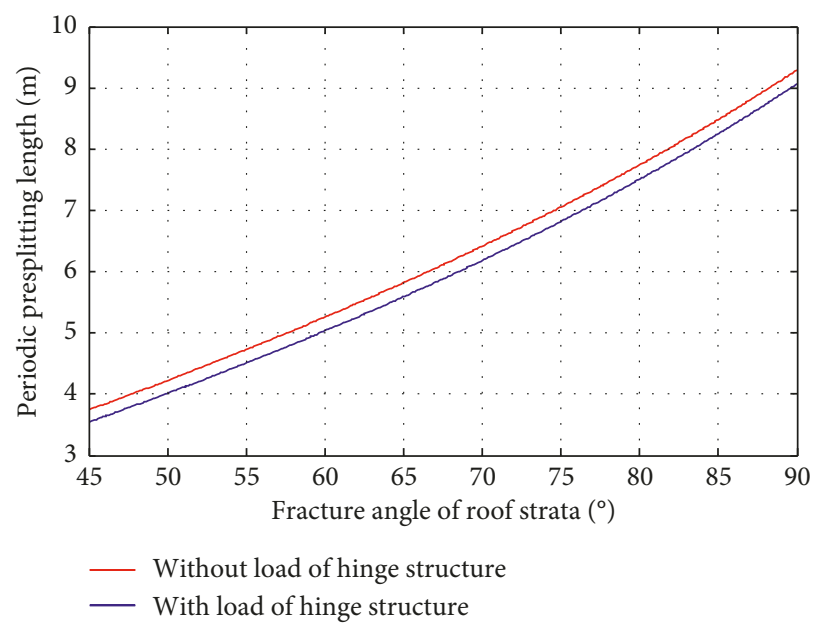

FIGURE 7: Relationship between the presplitting angle and periodic caving intervals. 


\section{Analysis on Fracturing Mechanism by Blasting}

In order to relieve the strata behaviors level, the key is to reduce the caving intervals for cutting off the loading transferring way and realizing the stress relief. DPB, because of the simple construction technology and strong adaptability, is widely used in presplitting the THR as an effective technology [10].

3.1. Fracturing Mechanism of the DPB. The DPB stimulates overpressure near blasting holes exceeding the dynamic compressive strength of the rock mass and forms a compression crushed zone (Crushed zone I). During the period, the pressure rapidly attenuates to the compression stress wave on the boundary of the crushed zone. After that, the radial fracture is induced by the reversely releasing of compressive stress and the main and wing cracks are interconnected, forming the initial concentric fracture network (Fractured zone, stage II) [23, 24].

After the initial crack forming, the detonation product diffuses uniformly in the fracture zone, which apply a quasistatic loading to the crack tip and produce the secondary propagation (Fractured zone, stage III). It penetrates through the fracturing zone induced by the detonation gas of the adjacent borehole, which achieves effective presplitting. The characteristic partition is shown in Figure 8.

3.1.1. Mechanism of Fracturing Induced by Stress Waves. The peak intensity of a transmitted shock wave generated by explosion of a cylindrical charge [25], $P_{m}$, is given by the following equation:

$$
P_{m}=n_{0} \frac{\rho_{0} D_{0}^{2}}{8} k_{\mathrm{r}}^{-2 \gamma} l_{c}^{-1},
$$

where $n_{0}$ is the stress intensification factor, $\rho_{0}$ is the explosive density, $D_{0}$ is the velocity of explosive, $k_{\mathrm{r}}=r_{\mathrm{c}} / r_{\mathrm{b}}, r_{\mathrm{c}}, r_{\mathrm{b}}$ are radius of blast hole and charge, respectively, $\gamma$ is the thermal insulation factor, 3 , and $l_{c}$ is the axial decoupling charge coefficient.

Combined with three-direction stress intensity coefficient $C$, the radius of crushing zone $R_{c}$ and the radius of the initial crack zone $R_{\mathrm{P}}$ are obtained, respectively [26]:

$$
\left\{\begin{array}{l}
C=\sqrt{(1+b)^{2}-2 \mu_{\mathrm{d}}(1-b)^{2}\left(1-\mu_{\mathrm{d}}\right)+\left(1+b^{2}\right)}, \\
R_{\mathrm{c}}=\left(P_{\mathrm{m}} \sqrt{2} C \frac{1}{\sigma_{\mathrm{c}} \xi^{1 / 3}}\right)^{1 / \alpha} r_{c}, \\
R_{\mathrm{P}}=\left[\left(\sqrt{2} \frac{C \sigma_{\mathrm{c}} \xi^{1 / 3}}{\sigma_{\mathrm{td}}+\left(q_{4}\right)_{3}+\gamma_{3} h_{3}}\right)^{1 / \beta}-1\right] \cdot\left[P_{m} C \frac{1}{\sigma_{\mathrm{c}} \xi^{1 / 3}}\right]^{1 / \beta} \cdot r_{c},
\end{array}\right.
$$

where $\sigma_{c}$ is the static uniaxial compressive strength, $\xi$ is the loading strain rate of the rock, $\sigma_{\mathrm{td}}$ is the dynamic uniaxial tensile strength, $b$ is the side pressure coefficient, $\alpha$ and $\beta$

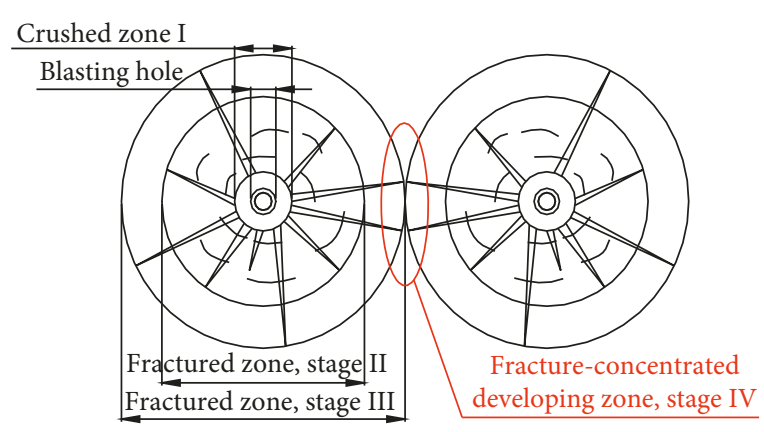

FIGURE 8: Blasting fracturing zone.

are shock and stress wave attenuation coefficients, $2+$ $b$ and $2-b$, respectively, and $\mu_{\mathrm{d}}$ is the dynamical Poisson ratio.

The fracturing characteristic curve of $k_{r}(1.0,1.11,1.25$, 1.5 , and 1.875$)$ on main cracks number and $\left(R_{\mathrm{c}}+R_{\mathrm{p}}\right)$ is shown in Figure 9. The variety on the fracturing length and number of main cracks took $k_{r}=1.25$ as an inflection point on the whole. With $k_{r}$ increasing $\left(k_{r} \leq 1.25\right)$, the length of main cracks slightly rose, and meanwhile, the number firstly increased and then kept stable. When $k_{r}>1.25$, the effect of the fracturing sharply dropped with both decreasing linearly. Therefore, $k_{r}$ was finally identified as 1.25.

Combined with Equation (14) and Table 2, $R_{\mathrm{c}}$ and $R_{\mathrm{p}}$ were set to be $0.13 \mathrm{~m}$ and $1.95 \mathrm{~m}$, respectively, obtaining $R_{\mathrm{c}}+$ $R_{\mathrm{p}}=2.08 \mathrm{~m}$.

\subsubsection{Mechanism of Crack Propagation Driven by Detonation} Gas. On the basis of the initial cracks, the detonation gas diffuses uniformly into the crack tip, resulting in the tensile yield and simulating the cracks secondary propagation. When the quasi-static pressure of detonation gas drops to the critical fracturing value of the brittle rock, the crack reaches the maximum length [14]. The ultimate pressure $\left(\sigma_{l}\right)$ is

$$
\sigma_{1}=\frac{K_{\mathrm{IC}}}{\sqrt{2 \pi\left(R_{C}+R_{\mathrm{p}}+l_{k(\max )}\right)}} .
$$

$K_{\text {IC }}$ is the static fracture toughness of rock mass and $l_{k(\max )}$ is the maximum length of secondary fracturing induced by detonation gas.

$K_{\text {IC }}$ could be measured experimentally as follows [27]:

$$
K_{\mathrm{IC}}=\frac{P_{\max }}{\pi B R} F \sqrt{\frac{\pi a}{2}}
$$

where $P_{\text {max }}$ is the peak loading of specimens, $a$ is the crack length, $B$ is the thickness, $R$ is the radius of the disc, and $F$ is the dimensionless stress intensity factor with a low loading rate, $F=1.0$. Test results are shown in Table 3 .

The detonation gas fracturing is mainly along the blasthole radial, and the maximum opening of the crack $u$ is in the boundary line of the initial crack zone. Based on the tip, the angle of cracks is $0^{\circ}$ approximately [28], the detonation gas in the isentropic diffusion, accords with 


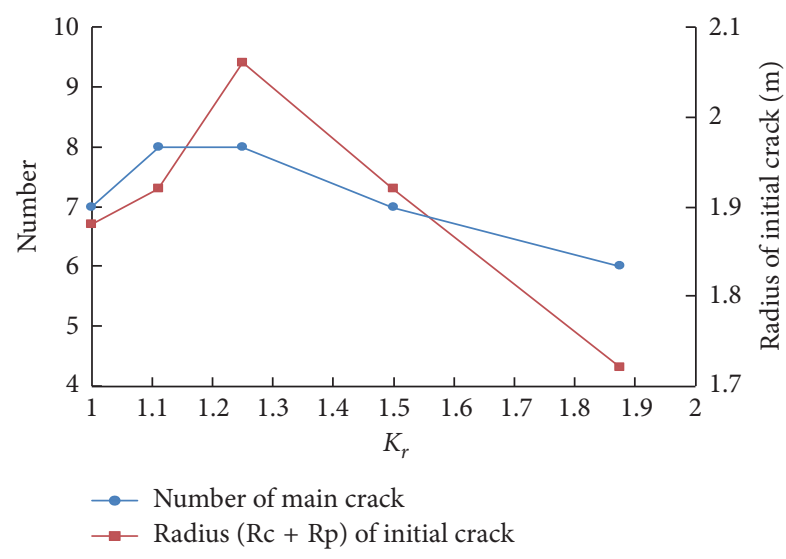

FIGURE 9: Effects of $k_{r}$ on the development of main cracks.

TABLE 2: Mechanical parameters of rock mass.

\begin{tabular}{ccccccc}
\hline$n_{0}$ & $\rho_{0}\left(\mathrm{~kg} / \mathrm{m}^{3}\right)$ & $D_{0}(\mathrm{~m} / \mathrm{s})$ & $b$ & $\mu_{d}$ & $\xi$ & $\sigma_{t d}(\mathrm{MPa})$ \\
\hline 10 & 1000 & 3200 & 0.25 & 0.2 & 1000 & 6.05 \\
\hline
\end{tabular}

$$
\left\{\begin{aligned}
p_{\mathrm{k}} & =p_{\mathrm{c}}\left[\frac{V_{\mathrm{c}}}{V}\right]^{\gamma}, \\
p_{k(\min )} & =\sigma_{\mathrm{c}}\left[1+\frac{n u\left(l_{k}(\max ) / 2+R_{\mathrm{p}}\right)}{\pi\left(r_{\mathrm{c}}+R_{\mathrm{c}}\right)^{2}}\right]^{\gamma}, \\
u & =\frac{K_{\mathrm{IC}}}{2 G} \sqrt{\frac{l_{(\max )}}{2 \pi \cos (\theta / 2)}}\left(\gamma+\cos \frac{\theta}{2}\right) \cos \frac{\theta}{4} \\
& \simeq \frac{K_{\mathrm{IC}}}{2 G} \sqrt{\frac{R_{\mathrm{p}}+l_{k(\max )}}{2 \pi}}(\gamma+1),
\end{aligned}\right.
$$

where $n$ is the number of main cracks and $G$ is the shear modulus.

Combined with Equation (17), the relationship between $l_{k(\max )}$ and $P_{x}$ could be obtained.

$$
\begin{aligned}
& \left(\frac{P_{k(\max )} \sqrt{2 \pi R_{C}+R_{\mathrm{p}}+l_{k(\max )}}}{K_{\mathrm{IC}}}\right)^{(1 /(k+1))} \\
& -\frac{n K_{\mathrm{IC}} \sqrt{\left(R_{\mathrm{p}}+l_{k(\max )}\right)}(k+1)\left(R_{\mathrm{p}}+(1 / 2) l_{k(\max )}\right)}{2 \sqrt{2 \pi} G \pi\left(R_{C}+r_{\mathrm{c}}\right)^{2}}-1=0 .
\end{aligned}
$$

Based on Figure 9, the development number of main crack is set to be $n=6-8$, and meanwhile, the number of main cracks in the mathematical model is 4-8 [29]; therefore, the number of main cracks for detonating gas diffusion is determined to be $4-8$. Figure 10 shows the relationship curve between $l_{k(\max )}$ and $P_{x}$.

As shown in Figure 10, $l_{k(\max )}$ is monotonically increased with $P_{x}$ and the number of main cracks has a significant effect on the fracturing length induced by detonation gas; that is, under the same fracturing length, the larger the number of main cracks is, the higher the critical gas pressure needed for crack propagation is. Combined with Equation (17), the steady pressure of detonation gas in initial cracks is calculated at $58.5 \mathrm{MPa}$. The maximum number of main cracks at present $(n=8)$ corresponds to $l_{k(\max )}=0.52 \mathrm{~m}$. Therefore, the length of secondary fracturing is $l_{k(\max )}=0.52 \mathrm{~m}$.

Then, the blast-hole spacing could be determined with $L$ $=2 l_{0}=2 \times\left(R_{c}+R_{p}+l_{k(\max )}\right)=2 \times(2.08+0.52)=5.20 \mathrm{~m}$. Therefore, the optimal blasting holes spacing is set at $5.0 \mathrm{~m}$.

\subsection{Analysis on the Numerical Simulation of $D P B$}

3.2.1. Numerical Model and Constitutive Equation. The LSDYNA is employed for establishing the 3-D model, and ALE is applied for analyzing the diffusion of detonation gas and the fracture evolution. Considering the computing time and simulation precision, the model size is set to be $20.0 \mathrm{~m} \times$ $12.0 \mathrm{~m} \times 15.0 \mathrm{~m}$ with nonreflecting boundary condition. Horizontal spacing of blast holes is made at intervals of $5.0 \mathrm{~m}$, with each having a cartridge diameter of $40 \mathrm{~mm}\left(k_{r}=\right.$ 1.25) and depth of $15.0 \mathrm{~m}$ through the whole model. Test points arrangement is shown in Figure 11.

According to the field construction and related contemporary research results, the numerical model and field experiment adopt the Class- 2 coal mine permissible emulsion explosive [30]. The MAT_PLASTIC_KINEMATIC and EOS_LINEAR_POLYNOMAL keyword offered by LSDYNA are employed for characterizing the blasting influential process on the rock. The parameters of MAT_HIGH_EXPLOSIVE_BURN and JWL Equation (19) are used for describing the relation between diffusion volume and pressure of crack tips, with explosive parameters shown in Table 4 [31, 32].

$$
P=A\left(1-\frac{\omega}{R_{1} V}\right) e^{R_{1} V}+B\left(1-\frac{\omega}{R_{2} V}\right) e^{R_{2} V}+\frac{\omega E}{V}
$$

$A, B, R_{1}, R_{2}$, and $\omega$ are the performance parameters of explosion, and $E_{0}$ and $V$ are the internal energy and volume of detonation gas, respectively.

Table 5 shows the rock mechanical parameters, and Table 6 presents the air status parameters.

3.2.2. Numerical Results and Analysis. In order to analyze the law of blast fracturing between blasting holes, numerical simulation with the DPB model $(L=5.0 \mathrm{~m})$ was employed for analyzing cracks evolution and rock particle vibration velocity.

(1) Dynamics of Cracks at a Cross Section. Figure 12 shows the dynamic evolution characteristics of the main and wing cracks at a cross section during blasting.

Figure 12 displays the fracture evolution in a profile vertical to the blast-hole axes. Figure 12(a) shows the morphological development of the crushed zone (region A) formed at $149.8 \mu \mathrm{s}$, with $R_{c}=0.12 \mathrm{~m}$. The diffusion 
TABLE 3: Fracture parameters of specimens.

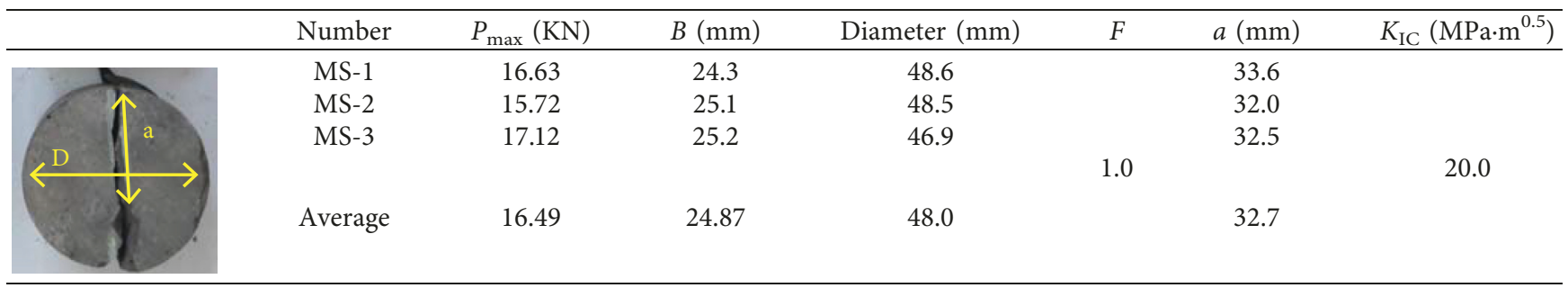

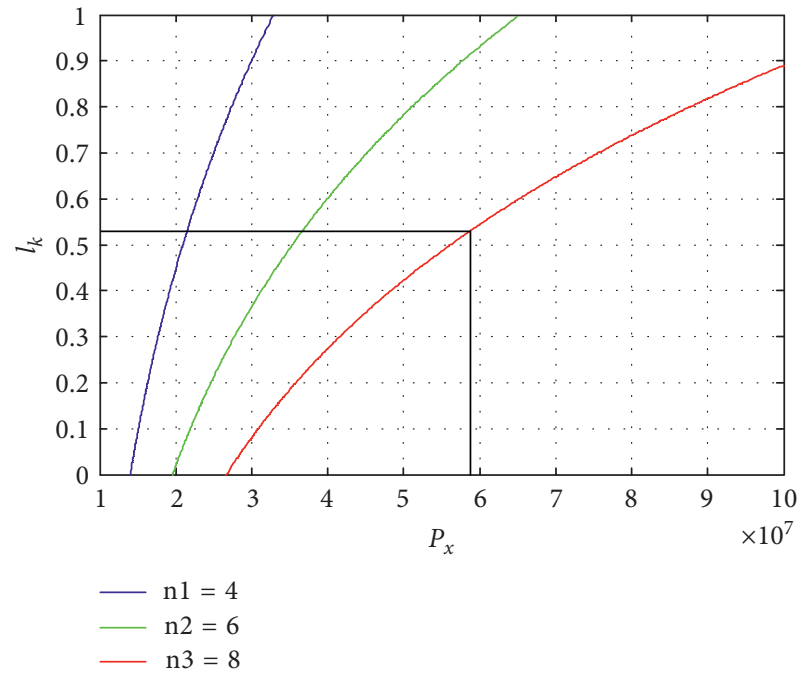

Figure 10: Effect of detonation gas acting on the secondary fracturing length.

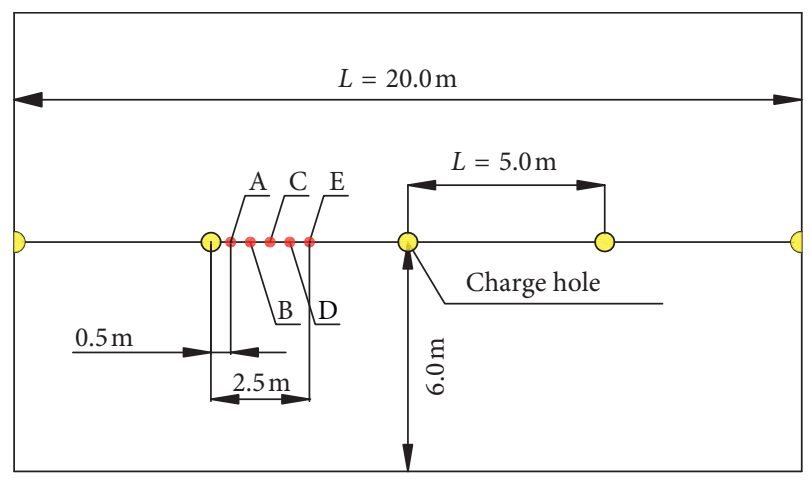

Figure 11: Model size and layout of observation points.

TABLE 4: Explosive parameters.

\begin{tabular}{lcccccccc}
\hline $\begin{array}{l}\text { Dens } \\
\left(\mathrm{kg} / \mathrm{m}^{3}\right)\end{array}$ & $V$ & \multicolumn{6}{c}{ State equation parameters } \\
& $(\mathrm{m} / \mathrm{s})$ & $A$ & $B$ & & & $E_{0}$ \\
& $(\mathrm{GPa})$ & $(\mathrm{GPa})$ & $R_{1}$ & $R_{2}$ & $\omega$ & $(\mathrm{GPa})$ \\
\hline 1000 & 3800 & 322 & 3.95 & 4.15 & 0.96 & 0.15 & 4.192 \\
\hline
\end{tabular}

boundary of detonation gas plotted in Figures 12(b) and 12 (c) depicted the radial fractured zone with a maximum radius of $1.93 \mathrm{~m}$ (Circular region $\mathrm{B}, \mathrm{t}=569.6 \mu \mathrm{s}$ ). The above showed the migration of detonation gas lagged behind the stress wave fracturing boundary before $349.3 \mu \mathrm{s}$. Then, the detonation gas led to steady propagation of secondary fracturing based on the initial cracks, the migrating boundary of which was synchronized with crack tip propagation. The fracturing rate of the detonation gas was much lower than that of the blasting stress. At $\mathrm{t}=569.6 \mu \mathrm{s}$, the secondary fracture propagated and interconnected with the initial fractures in region $B$ into penetrative fractures. Figure 12(d) was the stage of fracturing induced by detonating gas and density increasing after fracture penetration.

When the fracturing length of detonating gas was $0.4 \mathrm{~m}$, the fracture penetration further promoted the development of the wing cracks $\left(R_{k}=1.94 \mathrm{~m}\right)$ and the rock failed primarily with the direction vertical to the line passing through the holes center (red trajectory in region C). A mount of wing cracks occurred around the symmetry axis between two blast holes and strengthened the development degree of fracturing network and fragmentation lumpiness of the rock. Simulation results confirmed that the structural parameters of charge determined could ensure the favorable presplitting effect on the rock.

(2) Attenuation Law of Blasting Vibration Velocity on the Rock between Blast Holes. After blasting, the different vibration speed corresponds to the different rock damage degree. The higher the PPV of rock mass is, the greater the damage degree of the corresponding rock mass is $[33,34]$. The PPV critical value of the rock mass is shown in Table 7 $[35,36]$. Based on the integrity of $13.7 \mathrm{~m}$ medium sandstone, the demarcation point corresponding to the rock PPV is obtained.

Figure 13 shows the attenuation law of PPV at different positions on the blasting holes profile. In the direction of X, the particle vibration velocity presented the attenuation trend on the whole. The PPV of point A near the blasting hole was up to $38.96 \mathrm{~m} / \mathrm{s}$, resulting in the rock mass being approximately broken, and meanwhile, the PPV of point E was $3.35 \mathrm{~m} / \mathrm{s}$ exceeding the critical value of fracturing. The variation of PPV showed that DPB had a significant effect on the rock presplitted along the line through the holes center and the fracture intensive development in the middle of blast holes. In the direction of $\mathrm{Y}$, the PPV was obviously lower than that of $\mathrm{X}$ direction, indicating that the initial particle vibration was dominated by radial compression. After $400.0 \mu$ s, the particles $\mathrm{C}, \mathrm{D}$, and $\mathrm{E}$ showed a slight increase in the vibration velocity, which revealed that the detonation gas 
TABLe 5: Rock mechanical parameters.

\begin{tabular}{lccccccc}
\hline $\begin{array}{l}\text { Density } \\
\left(\mathrm{kg} / \mathrm{m}^{3}\right)\end{array}$ & $\begin{array}{c}\text { Elasticity } \\
\text { modulus } \\
(\mathrm{GPa})\end{array}$ & $\mu$ & $\begin{array}{c}\text { Yield } \\
\text { strength } \\
(\mathrm{MPa})\end{array}$ & $\begin{array}{c}\text { Tangent } \\
\text { modulus } \\
(\mathrm{GPa})\end{array}$ & $\begin{array}{c}\text { Hardening } \\
\text { coefficient }\end{array}$ & $\begin{array}{c}\text { Failure } \\
\text { strain }\end{array}$ & $\begin{array}{c}\mathrm{C}(\mathrm{s}) \\
P \text { value }\end{array}$ \\
\hline 2630 & 56.6 & 0.25 & 68.2 & 81.3 & 1.25 & 0.08 & 2.5 \\
\hline
\end{tabular}

TABle 6: Air status parameter.

\begin{tabular}{lccccc}
\hline Density $\left(\mathrm{kg} / \mathrm{m}^{3}\right)$ & $\mathrm{PC}(\mathrm{Pa})$ & $\mathrm{MU}$ & $C_{4}$ & $C_{5}$ & \\
\hline 1.252 & -1.0 & $1.75 \mathrm{e}-5$ & 0.4 & 0.4 & 1.0 \\
\hline
\end{tabular}

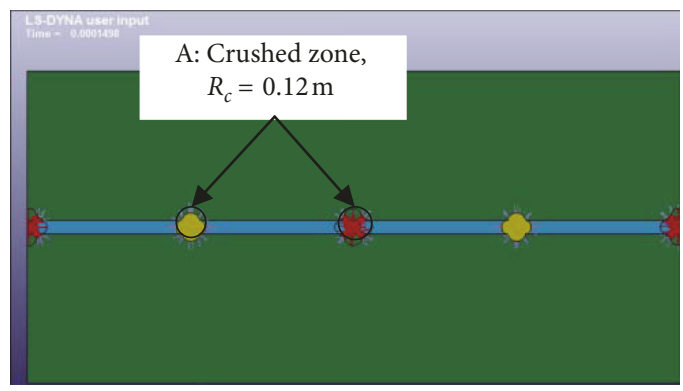

(a)

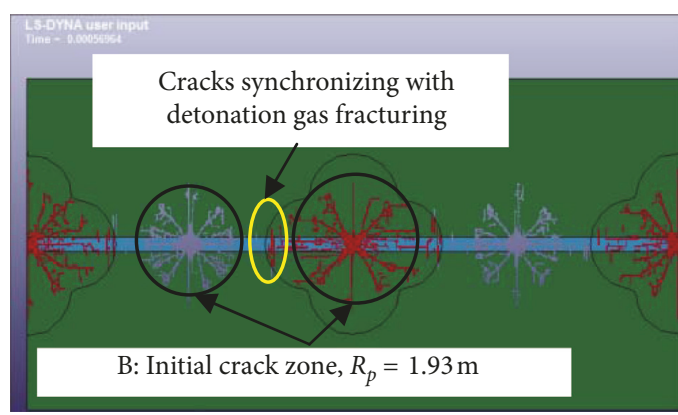

(c)

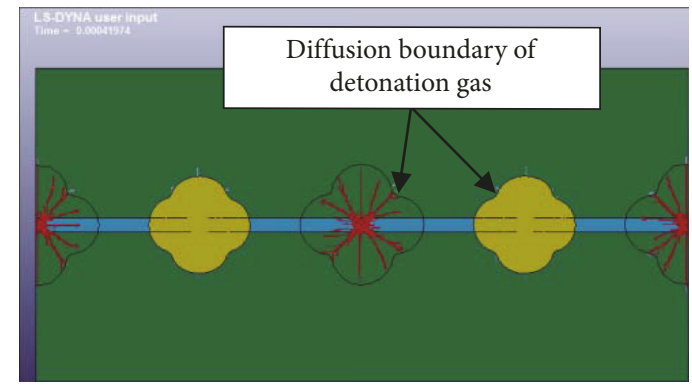

(b)

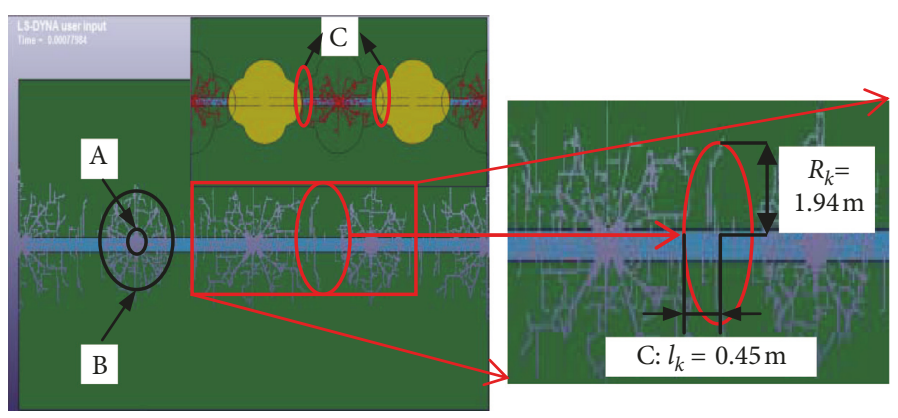

(d)

FIgURE 12: Evolution law of blasting-induced cracks (A: crushed zone; B: initial crack zone; C: the secondary fracturing length and interconnection zone induced by detonation gas). (a) $149.8 \mu \mathrm{s}$, (b) $349.3 \mu \mathrm{s}$, (c) $569.6 \mu \mathrm{s}$, and (d) $749.6 \mu \mathrm{s}$.

TABLE 7: PPV critical values.

\begin{tabular}{|c|c|c|}
\hline $\begin{array}{l}\text { Vibration } \\
\text { velocity } \\
(\mathrm{cm} / \mathrm{s}) \\
\end{array}$ & $\begin{array}{l}\text { Damage degree corresponding to } \\
\text { different vibration speeds }\end{array}$ & $\begin{array}{l}\text { Medium } \\
\text { sandstone } \\
\text { remark }\end{array}$ \\
\hline$<24$ & & - \\
\hline $26-6$ & fractures in rock & $31-47 \mathrm{~cm} / \mathrm{s}$ \\
\hline $63.5-$ & $\begin{array}{c}\text { The tensile crack is serious } \\
\text { stratas with radial cracks } \\
\text { developing }\end{array}$ & $48-170 \mathrm{~cm} / \mathrm{s}$ \\
\hline 255 & Rock mass is completely broken & $>171 \mathrm{~cm} / \mathrm{s}$ \\
\hline
\end{tabular}

lagging behind blasting stress wave simulated the particle vibration once more, promoted the secondary fracturing of cracks, and formed the interconnecting fractured network between the blasting holes. The PPV evolution indicated that the DPB in $13.7 \mathrm{~m}$ medium sandstone achieved the crushing and fracturing of the rock between the blasting holes, which showed the rationality and high efficiency of the blasting parameters.

\section{Field Application and Engineering Measurement}

4.1. Technological Parameters of Presplitting Blasting. Combining theoretical analysis and simulation results, it was determined that the initial and periodic caving intervals of the 8939 working face (key: $13.7 \mathrm{~m}$ medium sandstone) were $36.0 \mathrm{~m}$ and $8.0 \mathrm{~m}$, respectively. The technological parameters of DPB were determined and implemented. The arrangement of the presplitting blasting holes is shown in Figure 14 .

In the process of mining, the initial blasting fracturing of the THR was divided into 3 groups, in which the first was set at open-off cut and then the presplitting interval was $18.0 \mathrm{~m}$ (Twice). After implementing the initial caving presplitting of $13.7 \mathrm{~m}$ medium sandstone, the periodic interval of blasting 


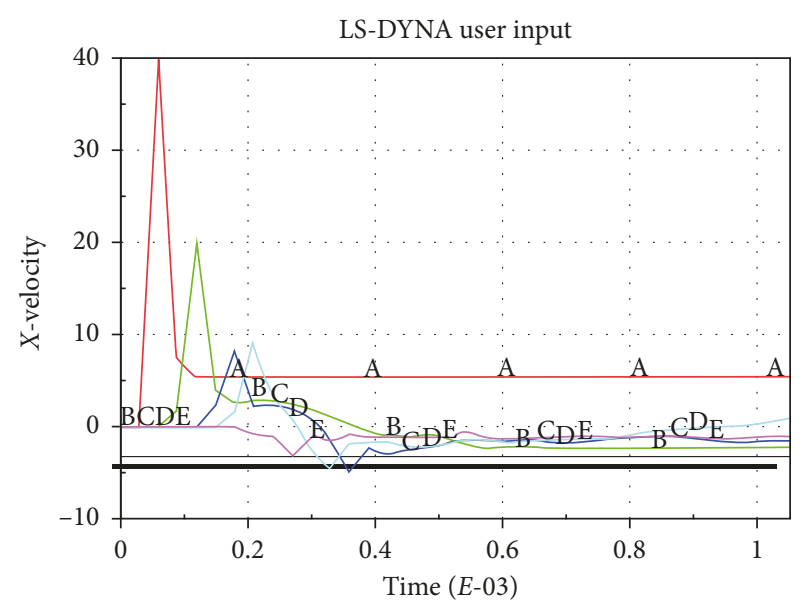
A 349461
B 349339
C 349327

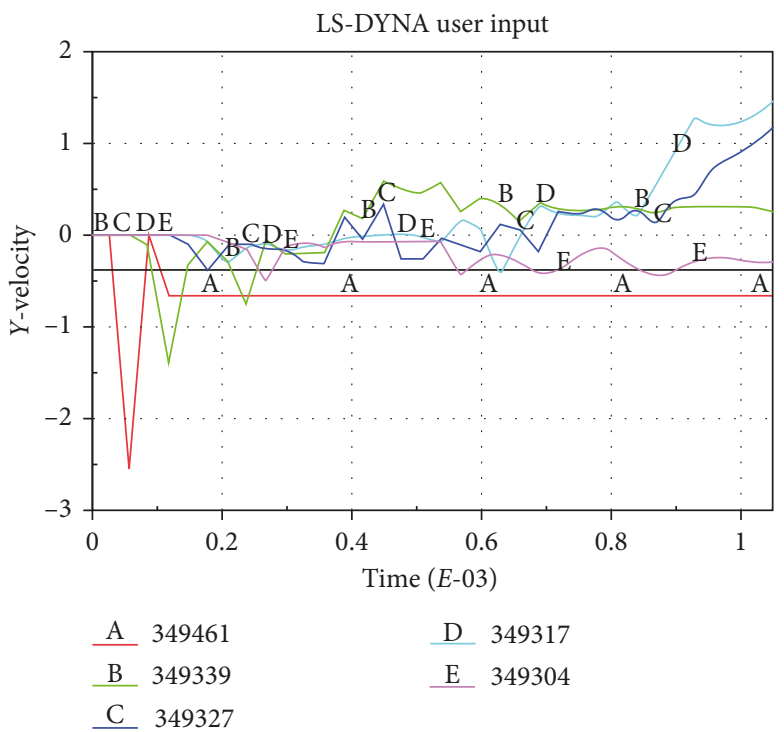

(b)

Figure 13: Attenuation curve of blasting velocity on the rock elements under different directions. (a)Horizontal direction (m/s). (b)Vertical direction $(\mathrm{m} / \mathrm{s})$.

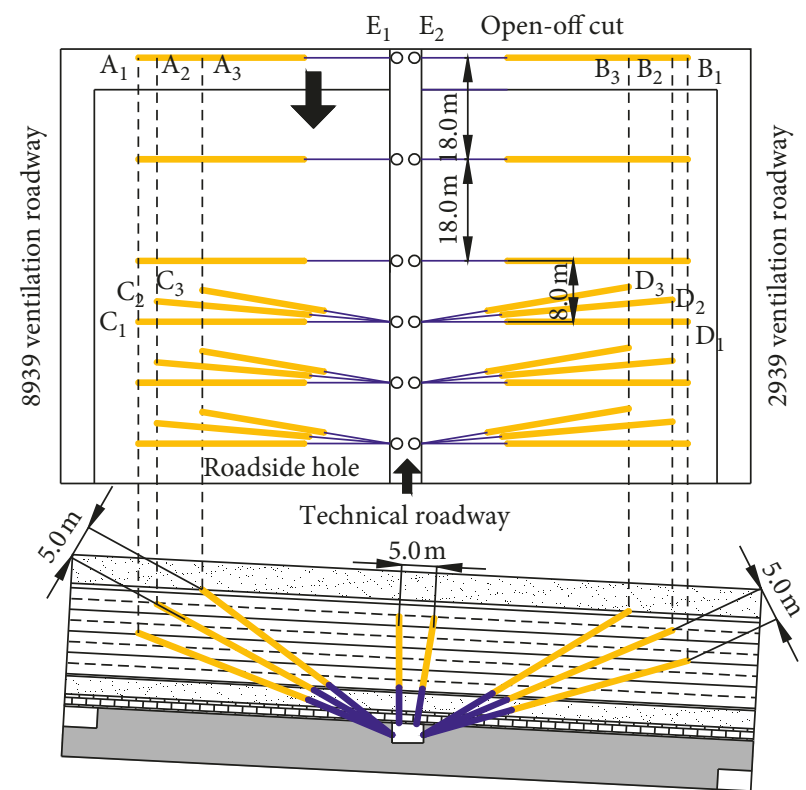

Figure 14: Plane and section view drawings of blasting presplitting holes.

presplitting was set to be $8.0 \mathrm{~m}$, and the distance between the drilling position and the floor was $1.2 \mathrm{~m}$. In order to avoid the process interferences, serial initiation of two boreholes was generally carried out during the maintenance crew, and the distance between initiation location of the periodic DPB and coal wall was $30 \mathrm{~m}$ at least.

A reverse charge was used in the blasting hole, in which the detonator and the first volume explosive were bundled at the bottom of the hole with the cartridge specification being $40 \mathrm{~mm} \times 500 \mathrm{~mm}$ (Figure 15(a)). The cartridge must be tight and the connection was reliable. The sealing section length was not less than $1 / 3$ of the holes depth, in which the rigid (concrete) was used in conjunction with plasticity (stemming) structure (Figures 15(b) and 15(c)). The stemming in middle cushioned the blasting energy, and the lower concrete resisted the residual energy (Figure 15(d)). The explosive and the sealing material are shown in Figure 15, and the charge structure is shown in Figure 16. The technical parameters of the roadside and roof presplitting holes are shown in Table 8. After blasting, drilling holes were tested to ensure the blasting effect.

4.2. Effectiveness of Blasting on the THR Controlling. After implementing presplitting blasting in the technical roadway, 


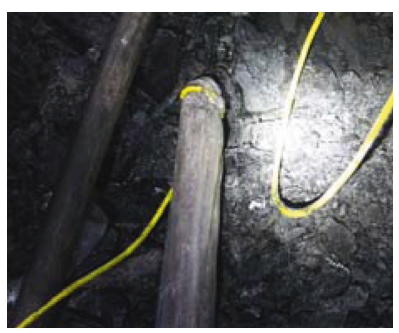

(a)

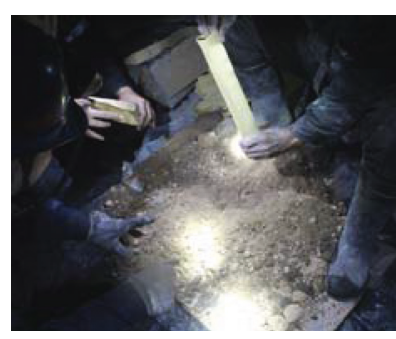

(b)

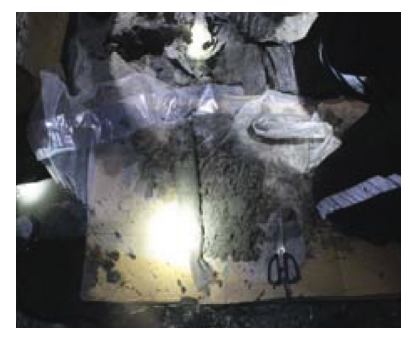

(c)

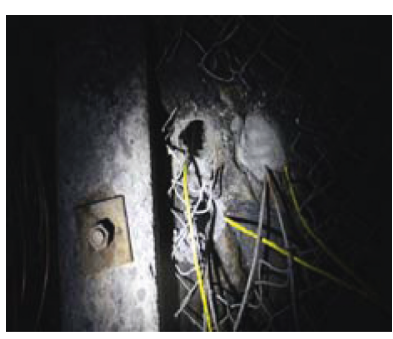

(d)

Figure 15: Cartridge and sealing material. (a) Powdery emulsion explosive binding, (b) stemming, (c) cement concrete, and (d) concrete sealing of blasting holes.



Figure 16: Schematic of the charge structure.

TABLE 8: Technical parameters of presplitting blast holes.

\begin{tabular}{|c|c|c|c|c|c|c|c|c|c|c|c|c|c|c|c|}
\hline \multirow{2}{*}{ Parameters } & \multirow{2}{*}{ Unit } & \multicolumn{6}{|c|}{ Primary blast presplitting } & \multicolumn{6}{|c|}{ Periodic blast presplitting } & \multicolumn{2}{|c|}{ Auxiliary blasting } \\
\hline & & $\mathrm{A}_{1}$ & $\mathrm{~B}_{1}$ & $\mathrm{~A}_{2}$ & $\mathrm{~B}_{2}$ & $\mathrm{~A}_{3}$ & $\mathrm{~B}_{3}$ & $\mathrm{C}_{1}$ & $\mathrm{D}_{1}$ & $\mathrm{C}_{2}$ & $\mathrm{D}_{2}$ & $\mathrm{C}_{3}$ & $\mathrm{D}_{3}$ & $E_{1}$ & $E_{2}$ \\
\hline Length & $\mathrm{m}$ & \multicolumn{2}{|c|}{39.2} & \multicolumn{2}{|c|}{38.7} & \multicolumn{2}{|c|}{34.5} & \multicolumn{2}{|c|}{39.2} & \multicolumn{2}{|c|}{38.9} & \multicolumn{2}{|c|}{35.1} & 15.7 & 15.8 \\
\hline Horizontal angle & $\circ$ & \multicolumn{6}{|c|}{0} & \multicolumn{2}{|c|}{0} & & & \multicolumn{2}{|c|}{7} & 0 & 0 \\
\hline Elevation angle & $\circ$ & 23 & 16 & 31 & 24 & 39 & 32 & 23 & 16 & 31 & 24 & 39 & 32 & 90 & 81 \\
\hline Sealing length & $\mathrm{m}$ & \multicolumn{2}{|c|}{13.2} & \multicolumn{2}{|c|}{13.2} & \multicolumn{2}{|c|}{11.5} & \multicolumn{2}{|c|}{13.2} & \multicolumn{2}{|c|}{13.4} & \multicolumn{2}{|c|}{11.6} & 5.2 & 5.3 \\
\hline Cement slug/Stemming & $\mathrm{m}$ & \multicolumn{2}{|c|}{$3.2 / 10.0$} & \multicolumn{2}{|c|}{$3.2 / 10.0$} & \multicolumn{2}{|c|}{$3.0 / 8.5$} & \multicolumn{2}{|c|}{$3.2 / 10.0$} & \multicolumn{2}{|c|}{$3.5 / 9.5$} & \multicolumn{2}{|c|}{$2.7 / 9.0$} & $1.2 / 4.0$ & $1.3 / 4.0$ \\
\hline Charge length & $\mathrm{m}$ & \multicolumn{2}{|c|}{26.0} & \multicolumn{2}{|c|}{25.5} & \multicolumn{2}{|c|}{23.0} & \multicolumn{2}{|c|}{26.0} & \multicolumn{2}{|c|}{25.5} & \multicolumn{2}{|c|}{23.5} & 10.5 & 10.5 \\
\hline Charge weight & $\mathrm{kg}$ & \multicolumn{2}{|c|}{31.2} & \multicolumn{2}{|c|}{30.6} & \multicolumn{2}{|c|}{27.6} & \multicolumn{2}{|c|}{31.2} & \multicolumn{2}{|c|}{30.6} & & & 12.6 & 12.6 \\
\hline
\end{tabular}

Tips: the single cartridge length is $0.5 \mathrm{~m}$ and the charge weight is $0.6 \mathrm{~kg}$.

the presplitting effecting of the THR was analyzed based on the field observation, including the working condition of supports and caving morphology.

Shapes of the presplitted roof collapse and characteristics of roadside instability in the technical roadway are shown in Figure 17.

The caving morphology of THR in the technical roadway was monitored while mining the working faces. When the working face was advanced near the blasting presplitting line, the presplitted roof was collapsed in time without suspended roof and lagging collapse, and the maximum size of the caved roof fragmentation was $2.5 \mathrm{~m} \times 2.0 \mathrm{~m}$ by visual measurement, as shown in Figure 17(a). Figure 17(b) reveals the destroyed degree on the roadside after DPB. The average width of the fractured zone was about $5.7 \mathrm{~m}$ with the maximum $8.0 \mathrm{~m}$, and the height was the whole roadside. Meanwhile, the maximum broken depth of the roadside near the blasting hole reached
$2.3 \mathrm{~m}$, and the bolts were completely flushed out of the roadsides. The above showed the good technical effect of DPB.

4.3. Working Resistance of the Supports. ZFS6000/22/35 type caving coal hydraulic support was applied for the 8939 working face mining. The characteristics of the support working resistance were monitored, as elaborated in Figure 18.

Figure 18(a) shows that, during mining, THR breaking led to "Minor-Major periodic weighting," in which a major weighting was usually accompanied by 2-4 minors. $13.7 \mathrm{~m}$ medium sandstone firstly collapsed with the working face advanced at $36.6 \mathrm{~m}$ and the work resistance was up to $5490 \mathrm{KN}$, which met the supporting strength. Then, with working face advanced, the sandstone formed "minor-periodic weighting" and periodic intervals were stable at $7.2 \mathrm{~m}-10.4 \mathrm{~m}$, coinciding 


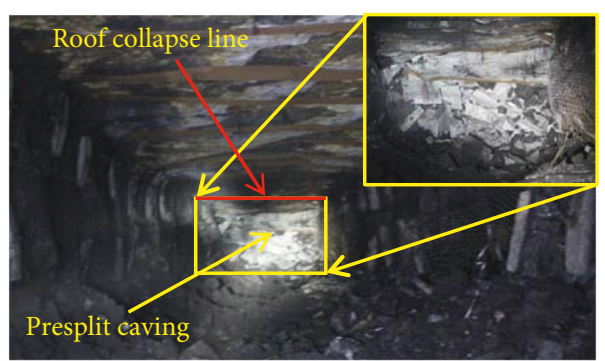

(a)
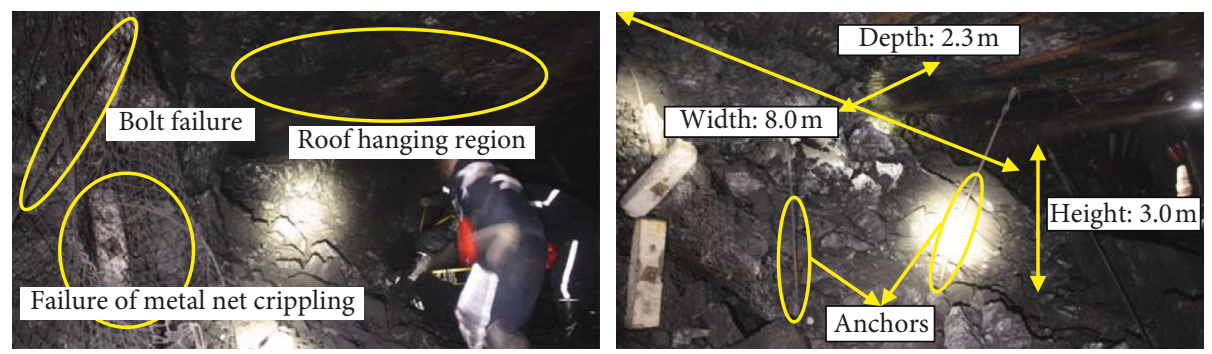

(b)

FIGURE 17: Shapes of the presplitted rock collapse and instability. (a) Roof collapse and (b) impact crushing of roadsides induced by blasting.

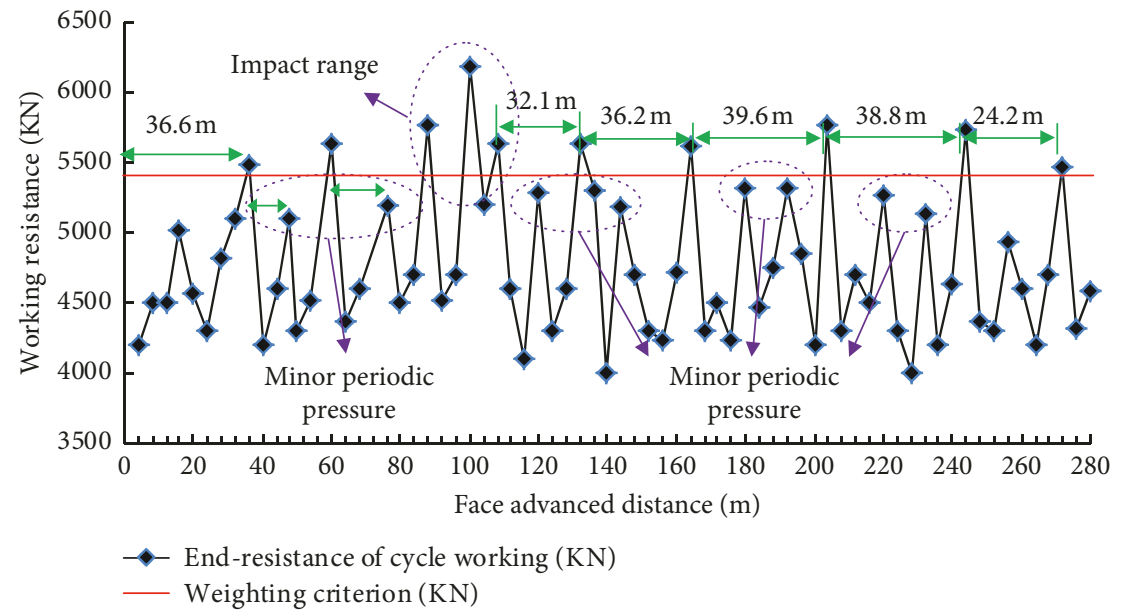

(a)

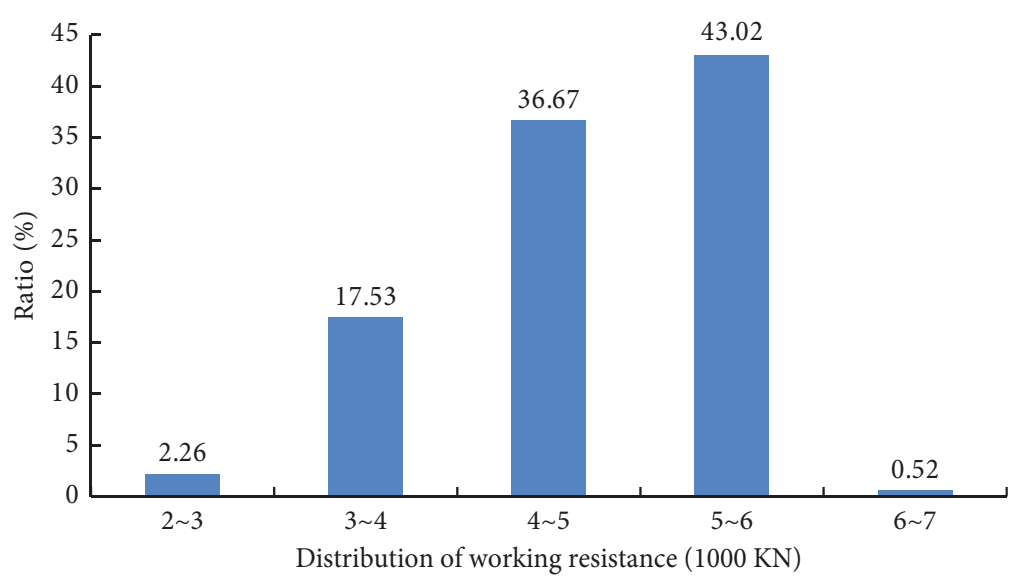

(b)

FIGURE 18: Strata behavior characteristics of the working face. (a) Hard roof caving characteristic and (b) interval distribution of supports resistance. 
with the theoretical analysis. When the working face was advanced at nearly $100.0 \mathrm{~m}, 14.2 \mathrm{~m}$ fine sandstone firstly collapsed, resulting in local strong strata behavior, and the maximum working resistance reached $6160 \mathrm{KN}$. Then, the periodic breaking interval of $13.7 \mathrm{~m}$ medium sandstone was $7.4 \mathrm{~m}-8.6 \mathrm{~m}$ and that of $14.2 \mathrm{~m}$ fine sandstone was $30.2 \mathrm{~m}-$ $38.8 \mathrm{~m}$. The maximum working resistance reached $5860 \mathrm{KN}$, matching with support type.

Figure 18(b) shows that the working resistance of the support largely located in the interval of $4000 \mathrm{KN}-6000 \mathrm{KN}$ and made up $79.69 \%$ of the totality, making the support capacity be used effectively. The time weighted working resistance was $4765 \mathrm{KN}$, accounting for $79.4 \%$ of the rated value $(6000 \mathrm{KN})$. Accordingly, the support had sufficient safety margins in the production process, ensuring the safe production.

\section{Conclusions}

On the basis of the controlled THR fracturing in the present study, the following conclusions can be drawn:

(1) The initial caving interval of the THR above the coal seam has been large. A large suspended roof gradually has been formed during the initial mining stage, and its rotation and sinking with fracture dynamic load have produced high side abutment pressure on the working face, which has been the main source of strong strata behaviors.

(2) The fracture mechanical model on the rock block articulated of the THR initial caving and the periodic caving of the cantilever beam is established. The relationship between the characteristics of the THR firstly fracturing and the support effecting is analyzed, obtaining the limit initial caving interval. Combined with the combined cantilever beam instability and characteristics of articulated rock stratum, the periodic caving interval and presplitting angle of the presplitted roof are obtained, with the optimal $L_{\text {aze }}=8.0 \mathrm{~m}$ and $\theta=0-7^{\circ}$.

(3) $\mathrm{DPB}$, as an effective presplitting technology, is employed for the THR fracturing. The length and characteristic zoning of DPB stress wave and detonation gas are calculated, respectively, and the influence factors of holes spacing are analyzed. Based on the results, the reasonable value of blasting technical parameters and holes spacing are optimized and determined.

(4) LS-DYNA3D was used for revealing the mechanism of crack propagation through evolution and interconnection of main and wing cracks. Meanwhile, the attenuation curve of PPV was obtained for analyzing rock damage scope. The result demonstrated that the rock between holes was successfully prefractured.

(5) A plan of blasting technological parameters on DPB was designed and applied in 8939 working face of Xinzhouyao Mine. Field measurement indicated that the blasting presplitted roof has achieved a timely and complete collapse. The DPB reduced the initial and periodic caving intervals effectively and the working resistance of the support was obviously reduced, which showed good control on the strata behavior. The remarkable technical effect has been obtained.

It should be noted that the limit caving intervals were obtained, only considering the static loading action of the articulated-strata and the broken THR. Because the additional dynamic loading induced by the fracturing of the lower THR and overlying strata, imposed on the supports, when the working face is advanced at about $100 \mathrm{~m}(14.2 \mathrm{~m}$ gritstone broken), the working resistance of the supports increases sharply to $6160 \mathrm{KN}$, exceeding the rated working resistance, which is larger than the theoretical calculation value.

Therefore, the future research emphasis is to supplement the calculation of the additional dynamic load applying on the supports, and simulate the characteristics of the dynamic fracturing and the relation between support and surrounding rocks under different presplitting caving intervals and angles for analyzing the THR controlling effect. Meanwhile, auxiliary holes should be added to observe the fracture evolution for analyzing presplitting effect before and after blasting in site.

\section{Data Availability}

All data used to support the findings of this study are available from the corresponding author upon request.

\section{Conflicts of Interest}

The authors declare no conflict of interest.

\section{Authors' Contributions}

Baobao Chen prepared the manuscript and performed the program design; Changyou Liu revised and reviewed the manuscript.

\section{Acknowledgments}

The authors gratefully acknowledge funding by National Natural Science Foundation of China (No. 51574220) and the Research and Innovation Project for College Graduates of Jiangsu Province (Grant no. KYLX16_0558).

\section{References}

[1] B. W. Xia, J. L. Jia, B. Yu, X. Zhang, and X. L. Li, "Coupling effects of coal pillars of thick coal seams in large-space stopes and hard stratum on mine pressure," International Journal of Mining Science and Technology, vol. 27, no. 6, pp. 965-972, 2017.

[2] X. M. Li, Z. H. Wang, and J. W. Zhang, "Stability of roof structure and its control in steeply inclined coal seams," International Journal of Mining Science and Technology, vol. 27, no. 2, pp. 359-364, 2017. 
[3] E. Ghasemi, H. Kalhori, and R. Bagherpour, "Stability assessment of hard rock pillars using two intelligent classification techniques: a comparative study," Tunnelling and Underground Space Technology, vol. 68, pp. 32-37, 2017.

[4] J. X. Yang, C. Y. Liu, and B. Yu, "The interaction between face support and surrounding rock and its rib weakening mechanism in hard coal seam," Acta Montanistica Slovaca, vol. 22, pp. 67-78, 2017.

[5] G. Raftoyiannis, C. C. Spyrakos, and G. T. Michaltsos, "Behavior of suspended roofs under blast loading," Engineering Structures, vol. 29, no. 1, pp. 88-100, 2007.

[6] Ramezanzadeh and M. Hood, "A state-of-the-art review of mechanical rock excavation technologies," Journal of Mining and Environment, vol. 1, no. 1, pp. 29-39, 2010.

[7] Y. Liu, J. X. Yang, and B. Yu, "Rock-breaking mechanism and experimental analysis of confined blasting of borehole surrounding rock," International Journal of Mining Science and Technology, vol. 27, no. 5, pp. 795-801, 2017.

[8] J. Z. Yu, T. J. Kuang, and X. B. Meng, "In situ investigations into overburden failures of a super-thick coal seam for longwall top coal caving," International Journal of Rock Mechanics and Mining Sciences, vol. 78, pp. 155-162, 2015.

[9] B. Marko, R. Celso, and R. Deane, "Finite element analysis of blast-induced fracture propagation in hard rocks," Computers and Structures, vol. 182, pp. 1-13, 2017.

[10] H. K. Verma, N. K. Samadhiya, M. Singh, R. K. Goel, and P. K. Singh, "Blast induced rock mass damage around tunnels," Tunnelling and Underground Space Technology, vol. 71, pp. 149-158, 2018.

[11] C. Y. Liu, J. X. Yang, B. Yu, and F. F. Wu, "Support resistance determination of fully mechanized top-coal caving face in extra thick seam under multi-layered hard strata," Journal of Mining and Safety Engineering, vol. 32, no. 1, pp. 7-13, 2015.

[12] B. Yu, J. X. Yang, and R. Gao, "Mechanism and technology of roof collaborative controlling in the process of Jurassic and Carboniferous coal mining in Datong mining area," Journal of China University of Mining and Technology, vol. 47, no. 3, pp. 486-493, 2018.

[13] F. T. Wang, S. H. Tu, Y. Yuan, Y. F. Feng, and F. Chen, "Deephole pre-split blasting mechanism and its application for controlled roof caving in shallow depth seams," International Journal of Rock Mechanics and Mining Sciences, vol. 64, pp. 112-121, 2013.

[14] J. X. Yang, C. Y. Liu, and B. Yu, "Application of confined blasting in water-filled deep holes to control strong rock pressure in hard rock mines," Energies, vol. 10, no. 11, p. 1874, 2017.

[15] J. G. Ning, J. Wang, L. S. Jiang, N. Jiang, X. S. Liu, and J. Q. Jiang, "Fracture analysis of double-layer hard and thick roof and the controlling effect on strata behavior: a case study," Engineering Failure Analysis, vol. 81, pp. 117-134, 2017.

[16] B. B. Mohanty, "Explosion generated fracture in rock and rock like materials," Engineering Fracture Mechanics, vol. 35, no. 45, pp. 889-898, 1990.

[17] H. M. Li, D. J. Jiang, and D. Y. Li, "Analysis of ground pressure and roof movement in fully-mechanized top coal caving with large mining height in ultra-thick seam," Journal of China Coal Society, vol. 39, no. 10, pp. 1956-1960, 2014.

[18] B. Unver and N. E. Yasitli, "Modelling of strata movement with a special reference to caving mechanism in thick seam coal mining," International Journal of Coal Geology, vol. 66, no. 4, pp. 227-252, 2006.
[19] H. Alehossein and B. A. Poulsen, "Stress analysis of longwall top coal caving," International Journal of Rock Mechanics and Mining Sciences, vol. 47, no. 1, pp. 30-41, 2010.

[20] Z. L. Xu, Elasticity Mechanics, Higher Education Press, Beijing, China, 2013.

[21] Q. X. Huang, M. G. Qian, and P. W. Shi, "Structural analysis of main roof stability during periodic weighting in longwall face," Journal of China Coal Society, vol. 24, no. 6, pp. 581-585, 1999.

[22] Z. L. Yang, "Stability of nearly horizontal roof strata in shallow seam longwall mining," International Journal of Rock Mechanics and Mining Sciences, vol. 47, no. 4, pp. 672-677, 2010.

[23] W. Lu, Z. Leng, M. Chen, P. Yan, and Y. Hu, "A modified model to calculate the size of the crushed zone around a blasthole," Journal of the South African Institute of Mining and Metallurgy, vol. 116, no. 5, pp. 413-422, 2016.

[24] R. Yang, W. F. Bawdens, and P. H. Katsabaniss, "A new constitutive model for blast damage," International Journal of Rock Mechanics and Mining Sciences and Geomechanics Abstracts, vol. 33, no. 3, pp. 245-254, 1996.

[25] J. Dai, "Calculation of radii of the broken and cracked areas in rock by a long charge explosion," Journal of Liaoning Technical University (Natural Science), vol. 20, no. 2, pp. 144-147, 2001.

[26] J. Dai, Rock Dynamic Characteristics and Blasting Theory, Press of Metallurgy Industry, Beijing, China, 2002.

[27] S. Zhang and Q. Z. Wang, "Determination of rock fracture toughness by split test using five types of disc specimens," Rock and Soil Mechanics, vol. 30, no. 1, pp. 12-18, 2009.

[28] T. Y. Fan, Principle and Application of Fracture Mechanics, Press of Beijing Institute of Technology, Beijing, China, 2006.

[29] R. K. Garnsworthy, "The mathematical modeling of rock fragmentation by high pressure arc discharges," in Proceedings of 3rd International Symposium on Rock Fragmentation by Blasting, pp. 143-147, Brisbane, Australia, August 1990.

[30] H. B. Li, X. Xia, J. C. Li, J. Zhao, B. Liu, and Y. Q. Liu, "Rock damage control in bedrock blasting excavation for a nuclear power plant," Journal of Mining Science and Technology, vol. 48, pp. 210-218, 2011.

[31] E. L. Lee and C. M. Tarver, "Phenomenological model of shock initiation in heterogeneous explosives," Physics of Fluids, vol. 23, pp. 2362-2372, 1980.

[32] Livermore Software Technology Corporation, LS-DYNA Keyword User's Manual, LSTC, Livermore, CA, USA, 2003.

[33] M. Monjezi, M. Hasanipanah, and M. Khandelwal, "Evaluation and prediction of blast-induced ground vibration at Shur River Dam, Iran, by artificial neural network," Neural Computing and Applications, vol. 22, no. 7-8, pp. 1637-1643, 2013.

[34] D. Jahed Armaghani, M. Hasanipanah, H. Bakhshandeh Amnieh, and E. Tonnizam Mohamad, "Feasibility of ICA in approximating ground vibration resulting from mine blasting," Neural Computing and Applications, vol. 29, no. 9, pp. 457-465, 2018.

[35] N. Fouladgar, M. Hasanipanah, and H. B. Amnieh, "Application of cuckoo search algorithm to estimate peak particle velocity in mine blasting," Engineering with Computers, vol. 33, no. 2, pp. 181-189, 2017.

[36] M. Hasanipanah, R. Shirani Faradonbeh, H. Bakhshandeh Amnieh, D. Jahed Armaghani, and M. Monjezi, "Forecasting blast-induced ground vibration developing a CART model," Engineering with Computers, vol. 33, no. 2, pp. 307-316, 2017. 


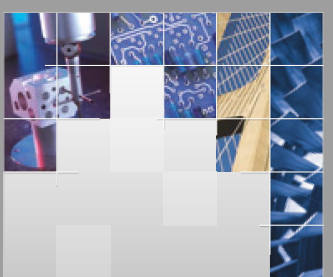

\section{Enfincering}
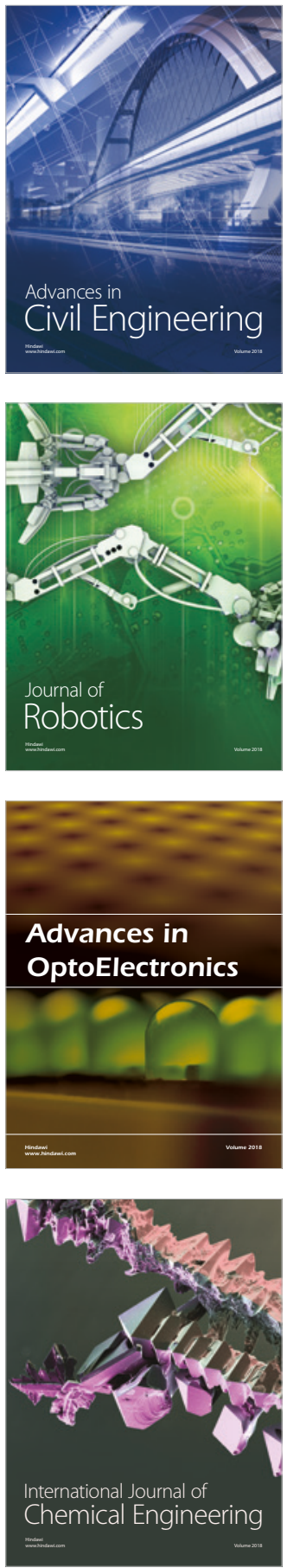

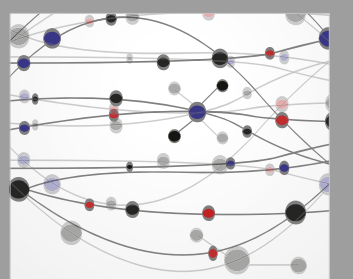

\section{Rotating \\ Machinery}

The Scientific World Journal

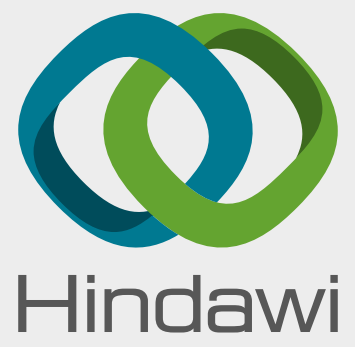

Submit your manuscripts at

www.hindawi.com

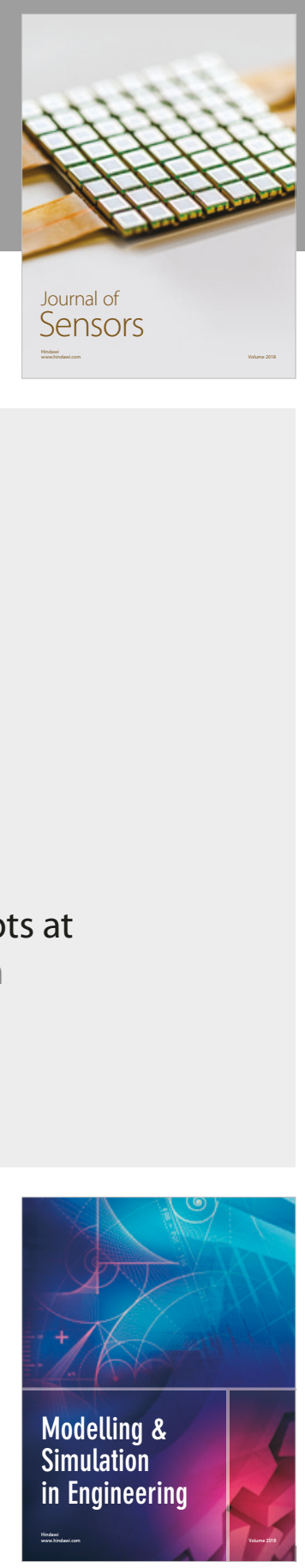

\section{Advances \\ Multimedia}
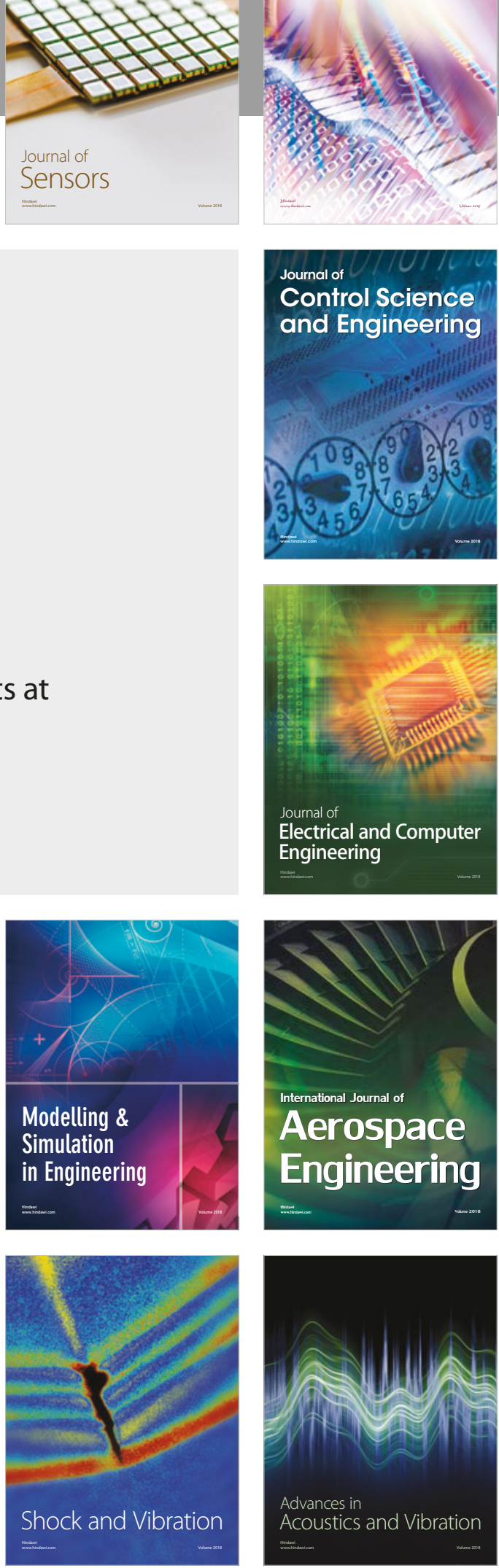